\title{
Adherence and persistence rates of major antidiabetic medications: a review
}

\author{
David Seung U. Lee Le $^{1,4}$ and Howard Lee ${\text { Le, } 2,3,4,5^{*}}_{\text {(D) }}$
}

\begin{abstract}
The objective of this paper was to review the adherence and persistence rates of major antidiabetic medication classes (i.e., metformin, sulfonylureas, sodium glucose cotransporter-2 inhibitors, dipeptidyl peptidase-4 inhibitors, insulin, glucagon-like peptide-1 receptor agonists, and thiazolidinediones) by summarizing the major findings of the studies published since 2017. In addition, we reported the potential causes for low adherence and persistence of antidiabetic medications. Based on the literature, the highest rate of adherence and persistence was consistently observed in metformin users. Second to metformin were sodium glucose cotransporter-2 inhibitors. Injectable therapies such as insulin and glucagon-like peptide-1 receptor agonists trailed low on the adherence and persistence rates. To the best of our knowledge, no studies published since the year 2017 analyzed the adherence and persistence of thiazolidinediones independently. The most frequently cited cause for low adherence and persistence was the severity of adverse events. Baseline characteristics (e.g., baseline HbA1c level), demographic information (e.g., age, gender, or ethnicity), and comorbidity profiles also had significant impacts on adherence and persistence in patients with type 2 diabetes mellitus.
\end{abstract}

Keywords: Diabetes mellitus, Adherence, Persistence, Antidiabetic medications, Hypoglycemic agents

\section{Background}

Adequate management of chronic disease is difficult. Patients are often required to take one or more medications over the entire lifespan of the disease [1]. Management of chronic disease is further complicated by two patterns of medication non-use: (1) missed medication doses (termed non-adherence in this study) and (2) abrupt discontinuation or substantial medication gap (termed non-persistence or discontinuation in this study) [2]. In developed countries, average adherence to medications for chronic diseases is as low as $50 \%$, while the measure is lower in developing countries due to limited access to healthcare resources [3, 4]. Medication non-use aggravates the burden of chronic diseases and clinical

\footnotetext{
*Correspondence: howardlee@snu.ac.kr

${ }^{3}$ Department of Clinical Pharmacology and Therapeutics, Seoul National University College of Medicine and Hospital, 103 Daehak-ro, Jongno-gu, Seoul 110-799, Republic of Korea

Full list of author information is available at the end of the article
}

outcomes of patients $[4,5]$. Therefore, ensuring adherence and persistence of medications is key to successful management of chronic disease.

Poor adherence and persistence remain a barrier to optimal care for patients with type 2 diabetes mellitus (T2DM) [6-9]. A systematic review found that only $56.2 \%$ in T2DM patients continued treatment one year after treatment initiation [10]. Adherence and persistence to injection drugs are even lower. The persistence rate of insulin glargine in the first year after initiation is below 50\% [11]. Suboptimal persistence undermines clinical outcomes, leading to poor glycemic control [12, $13]$ and increases mortality and comorbidity burden [14, 15]. Moreover, low adherence to antidiabetic medications increases healthcare costs and diminishes quality of life $[5,14,16]$.

The causes of low adherence and persistence to T2DM medications are multifactorial [17]. The World Health Organization classified reasons for medication non-use into five categories: patient-related (e.g., age),

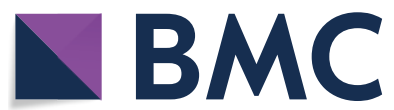

(c) The Author(s) 2022. Open Access This article is licensed under a Creative Commons Attribution 4.0 International License, which permits use, sharing, adaptation, distribution and reproduction in any medium or format, as long as you give appropriate credit to the original author(s) and the source, provide a link to the Creative Commons licence, and indicate if changes were made. The images or other third party material in this article are included in the article's Creative Commons licence, unless indicated otherwise in a credit line to the material. If material is not included in the article's Creative Commons licence and your intended use is not permitted by statutory regulation or exceeds the permitted use, you will need to obtain permission directly from the copyright holder. To view a copy of this licence, visit http://creativecommons.org/licenses/by/4.0/. The Creative Commons Public Domain Dedication waiver (http://creativecommons.org/publicdomain/zero/1.0/) applies to the data made available in this article, unless otherwise stated in a credit line to the data. 
socioeconomic (e.g., medication costs), condition-related (e.g., presence of complications), health-system-related (e.g., level of continuity of care), and medication-related (e.g., adverse effects) [4]. Similarly, motivations behind medication non-use in T2DM patients on injection therapies are multifaceted. Ineffective communication between patients and providers, inadequate knowledge about medications, and confusing directions for medication use simultaneously undermine treatment processes [18]. Moreover, the classes of antidiabetic medication influence the adherence and persistence to the treatment $[1,19]$.

The objective of this paper was to review the latest adherence and persistence rates of major antidiabetic medication classes chosen based on their proportional market shares [20]. Moreover, we compared the adherence and persistence rates of individual antidiabetic medications within the same medication class. Moreover, we investigated the potential causes for low adherence and persistence of antidiabetic medications. To this end, we summarized the major findings of the studies published since 2017. The year 2017 was chosen to account for the shift in pharmacological diabetes treatment pattern, as reflected in the medications' proportional market shares [20], due in large part to the accelerating acceptance and widespread use of such medication classes as sodium glucose co-transporter 2 inhibitors and glucagon-like peptide-1 receptor agonists. Published studies on the topic of adherence and persistence of the selected antidiabetic medications were identified by searching the four databases, i.e., PubMed, Cochrane Library, Google Scholar, and Embase. This information will help guide clinical decisions to optimize treatment adherence and persistence in patients with T2DM while reducing complications and healthcare costs. A precise understanding about the causes of medication non-use will also assist the development of new antidiabetic drugs and delivery devices better equipped to improve adherence and persistence. The key findings of previous studies that analyzed the adherence and persistence of various antidiabetic medications are summarized in Table 1.

\section{Metformin}

Metformin is well-tolerated and economic [21, 22], making it suitable for long-term treatment of T2DM. Furthermore, metformin has demonstrated the highest adherence and persistence rates in antidiabetic medications [2]. However, the adherence and persistence of metformin is still suboptimal $[10,23]$. For example, the lowest daily medication possession probability (MPP) of metformin-i.e., the sum of days supplied by prescription fills during follow-up divided by the number of days in follow-up [24] - was only 0.46 [7]. Given that MPP $\geq 0.8$ is generally accepted as the cut-off value for good adherence [25], the MPP value of 0.46 is certainly not optimal for a foundation medication like metformin. Likewise, the percentage of metformin users who continued treatment for one year ranged between 62.8 and $73.6 \%$ [26, 27]. The share of persistent metformin users declined to $48.5 \%$ and $27.7 \%$ at the end of second and fifth years of follow-up, respectively [26].

Baseline characteristics affect the adherence and persistence of metformin therapy. Higher baseline glycated hemoglobin (HbA1c) was associated with significantly lower rate of discontinuation. A percentage point increase in $\mathrm{HbA} 1 \mathrm{c}$ was associated with $30 \%$ lower metformin persistence (95\% confidence interval [95\% CI]: $15-45 \%$ ) [28]. Older patients were more persistent. For example, one year increase in age was associated with significantly better persistence (odds ratio or OR [95\% CI]: 1.02 [1.02-1.02], $\mathrm{p}<0.001$ ) [29]. Using lower dose metformin (500 $\mathrm{mg}$ as opposed to $1000 \mathrm{mg}$ ) was associated with significantly lower discontinuation rate (OR [95\% $\mathrm{CI}$ ] of discontinuation of $500 \mathrm{mg}$ metformin: 0.54 [0.370.76], $\mathrm{p}<0.01$ ) [28]. Similarly, taking fewer concomitant medication was associated with significantly better persistence (OR [95\% CI]: 1.27 [1.20-1.33], p < 0.001) [29]. Patients using extended-release formulation were significantly more persistent than patients using immediate-release formulation (OR [95\% CI] of persistence of extended-release formulation: 1.14 [1.10-1.18], $\mathrm{p}<0.001$ ) [30]. Table 2 summarizes the factors affecting the adherence and persistence of metformin therapy.

\section{Sulfonylureas}

Sulfonylureas (including chlorpropamide, tolazamide, glipizide, glyburide, and glimepiride) are frequently prescribed to T2DM patients as second-line therapy despite potential hypoglycemic risks [20]. For sulfonylurea users, the proportion of days covered (PDC), or the number of days covered by prescription fills divided by the number of days between the first fill of the medication and the end of the measurement period [24], ranged from 0.62 and $0.72[31,32]$. The percentage of patients who continued to take sulfonylureas at one year ranged between 50.4 and $68.9 \%$ [27, 31]. The longer the treatment period, the lower the persistence. For example, the percentage of patients who continued to take sulfonylureas declined to $51.3 \%, 47.1 \%$, and $31.6 \%$ at the end of two, three and five years of follow-up, respectively $[1,32]$.

Sulfonylurea users were significantly less persistent than metformin users (hazard ratio or HR $[95 \% \mathrm{CI}]$ of discontinuation of sulfonylureas: 1.2 [1.16-1.24], $\mathrm{p}<0.001$ ) [1]. Moreover, the percentage of adherent patients (PDC $\geq 0.8$ ) who used sulfonylurea as an add-on to metformin was significantly lower than that of patients 


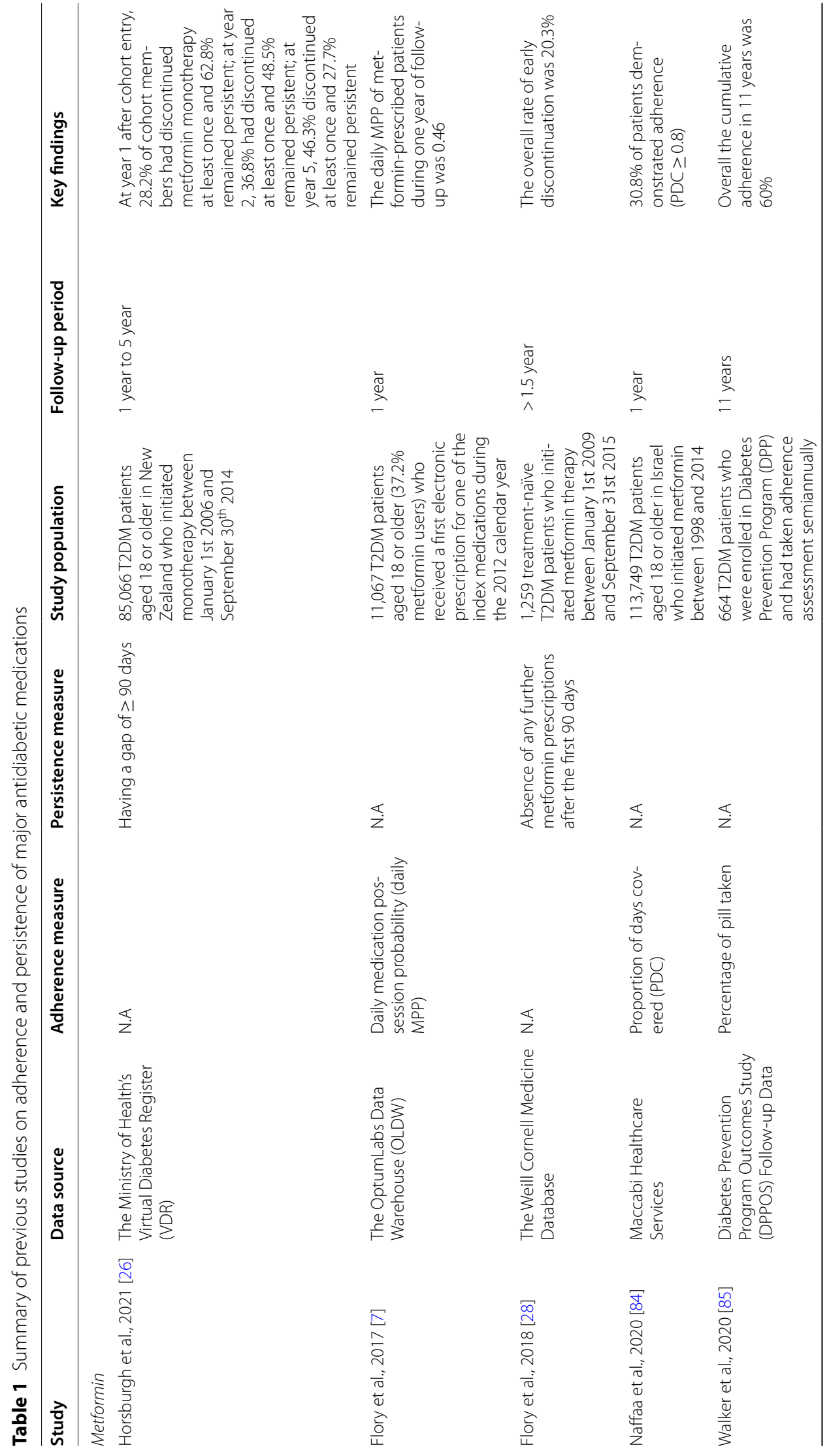




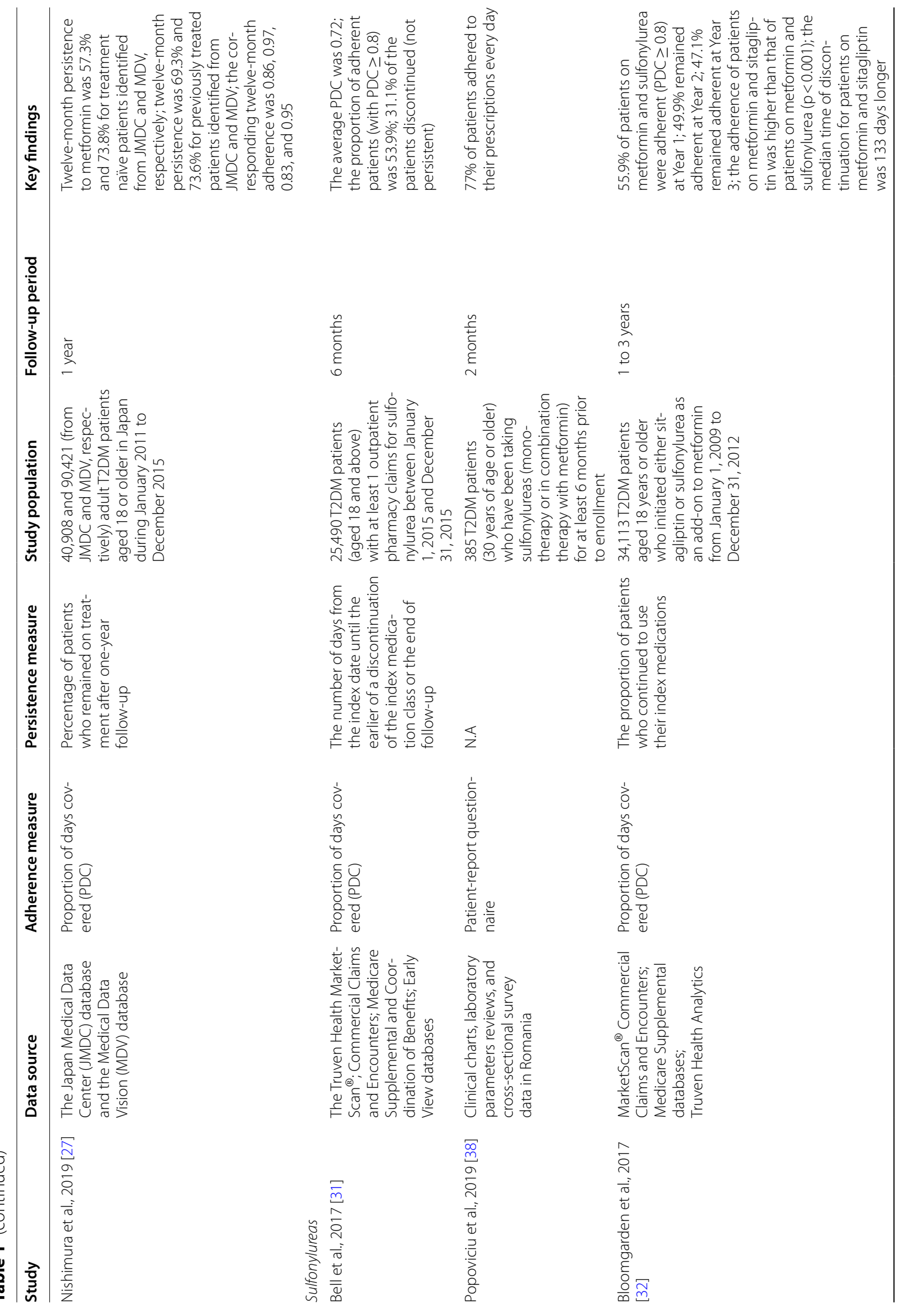




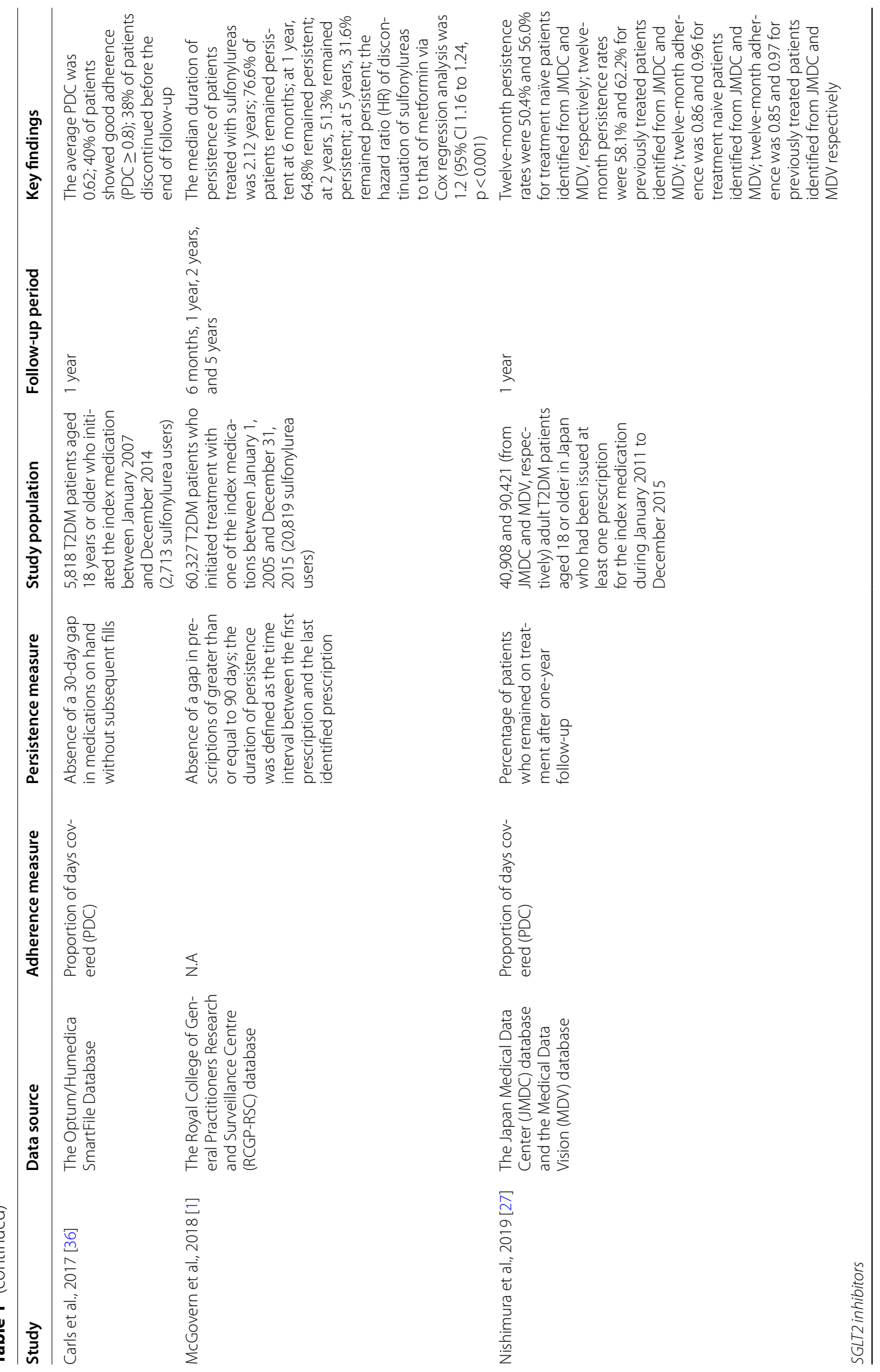




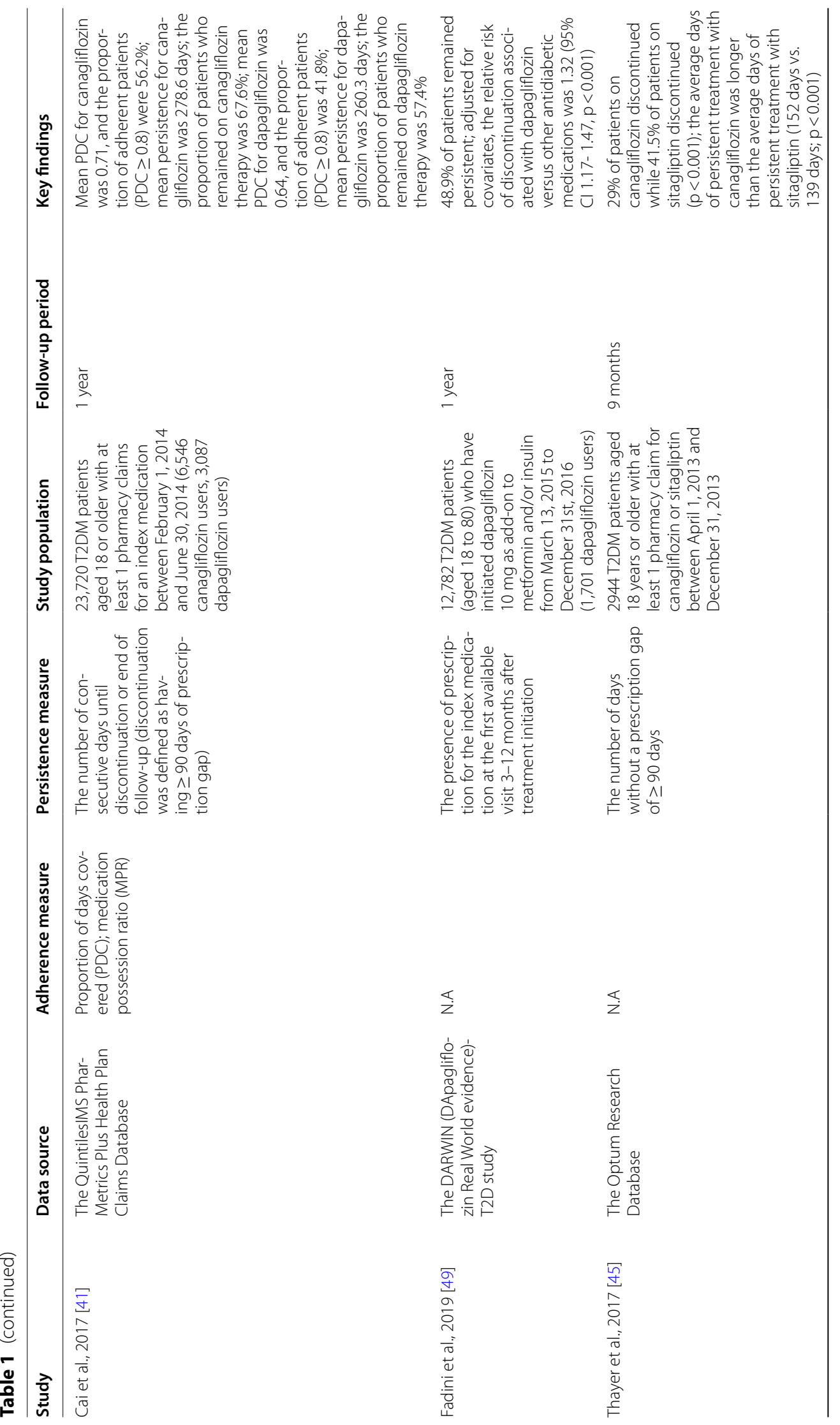




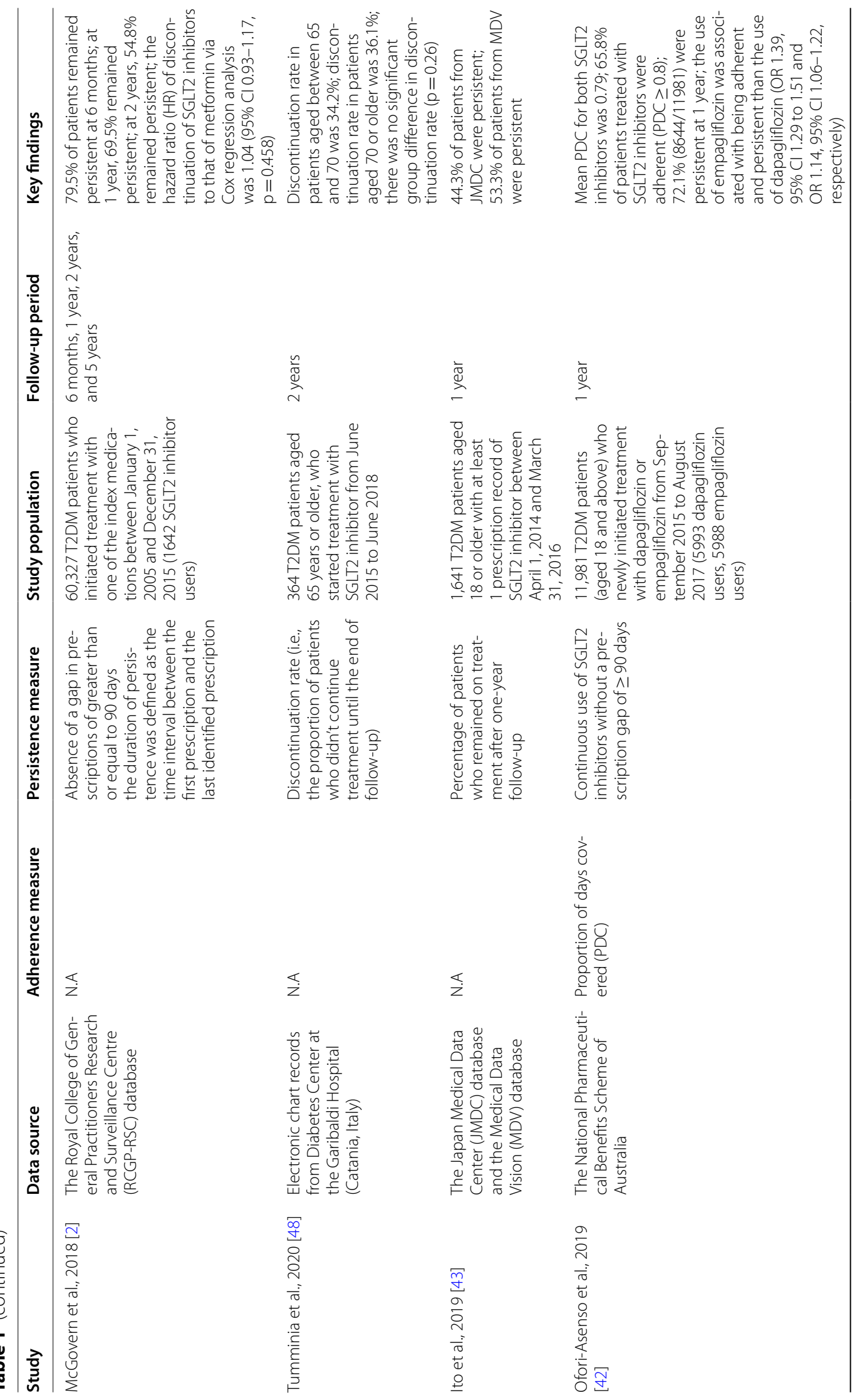




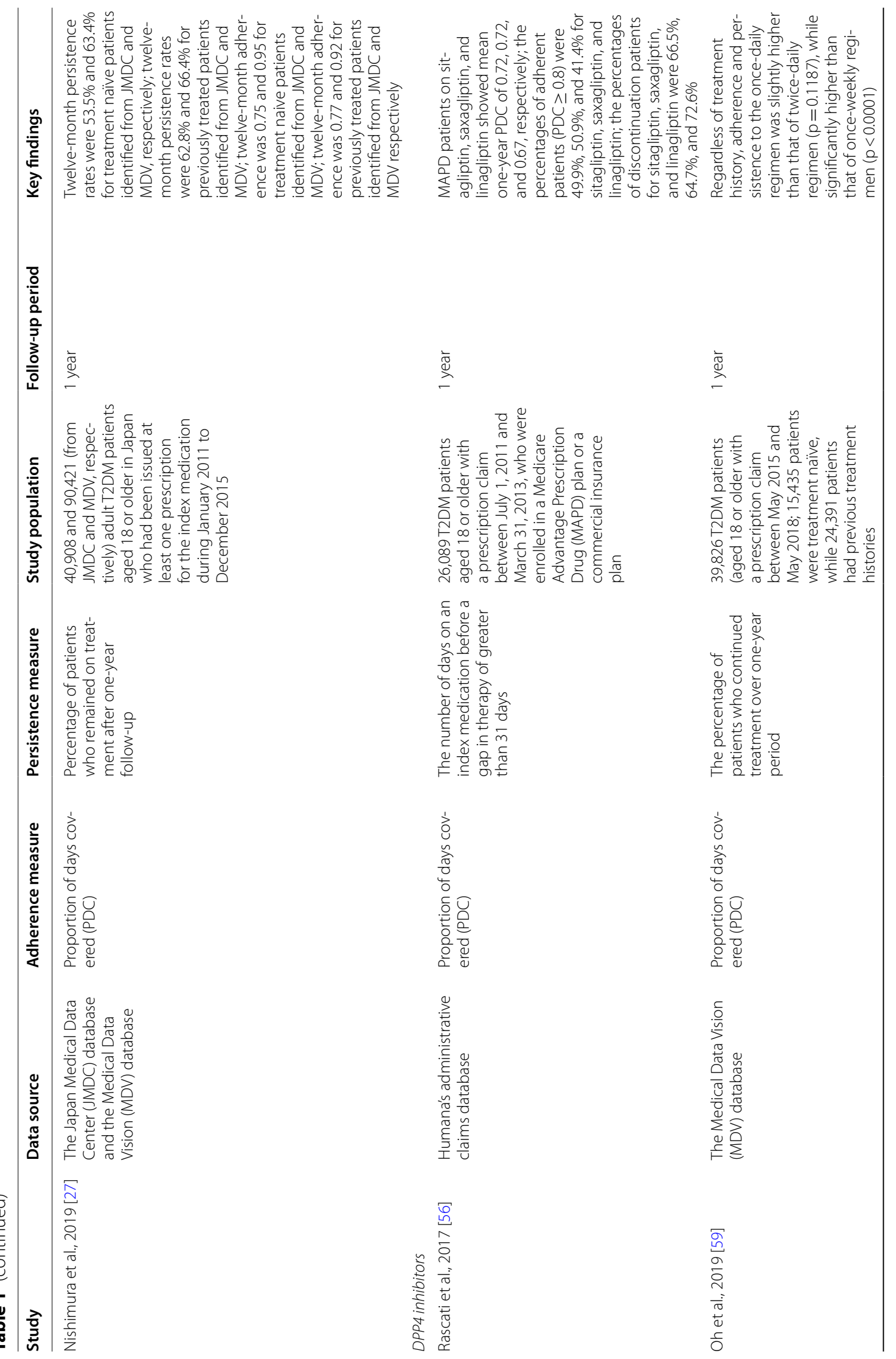




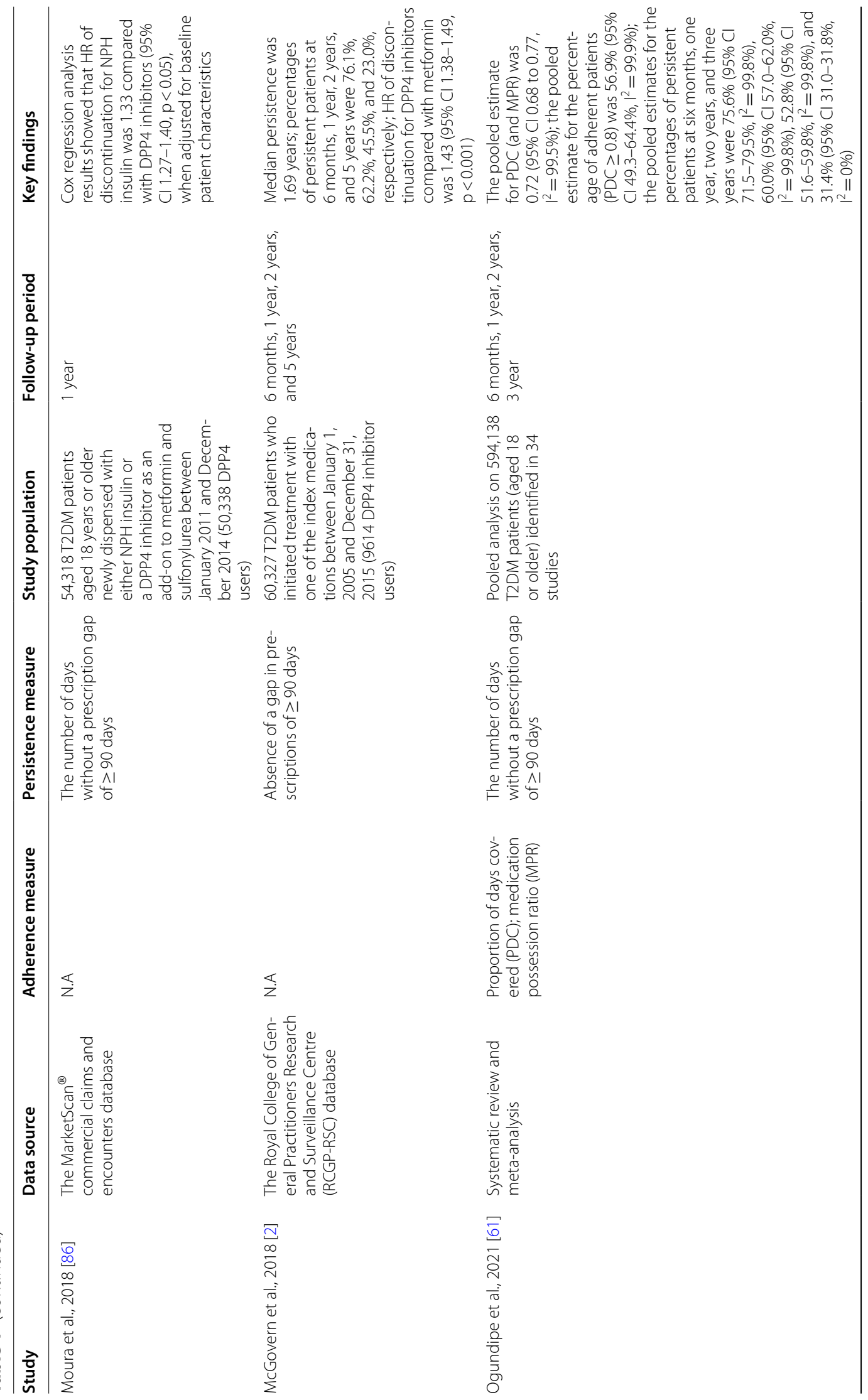




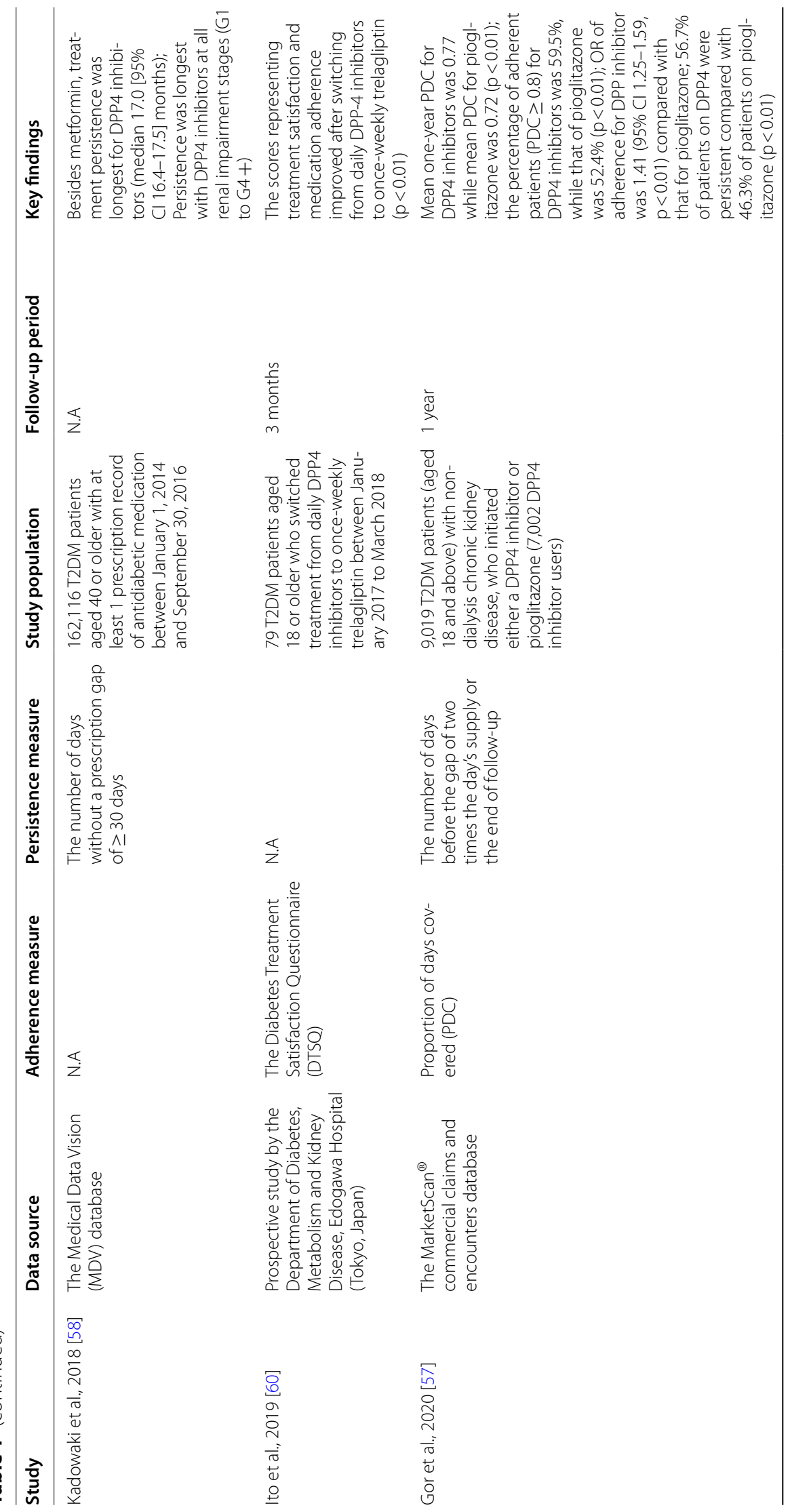




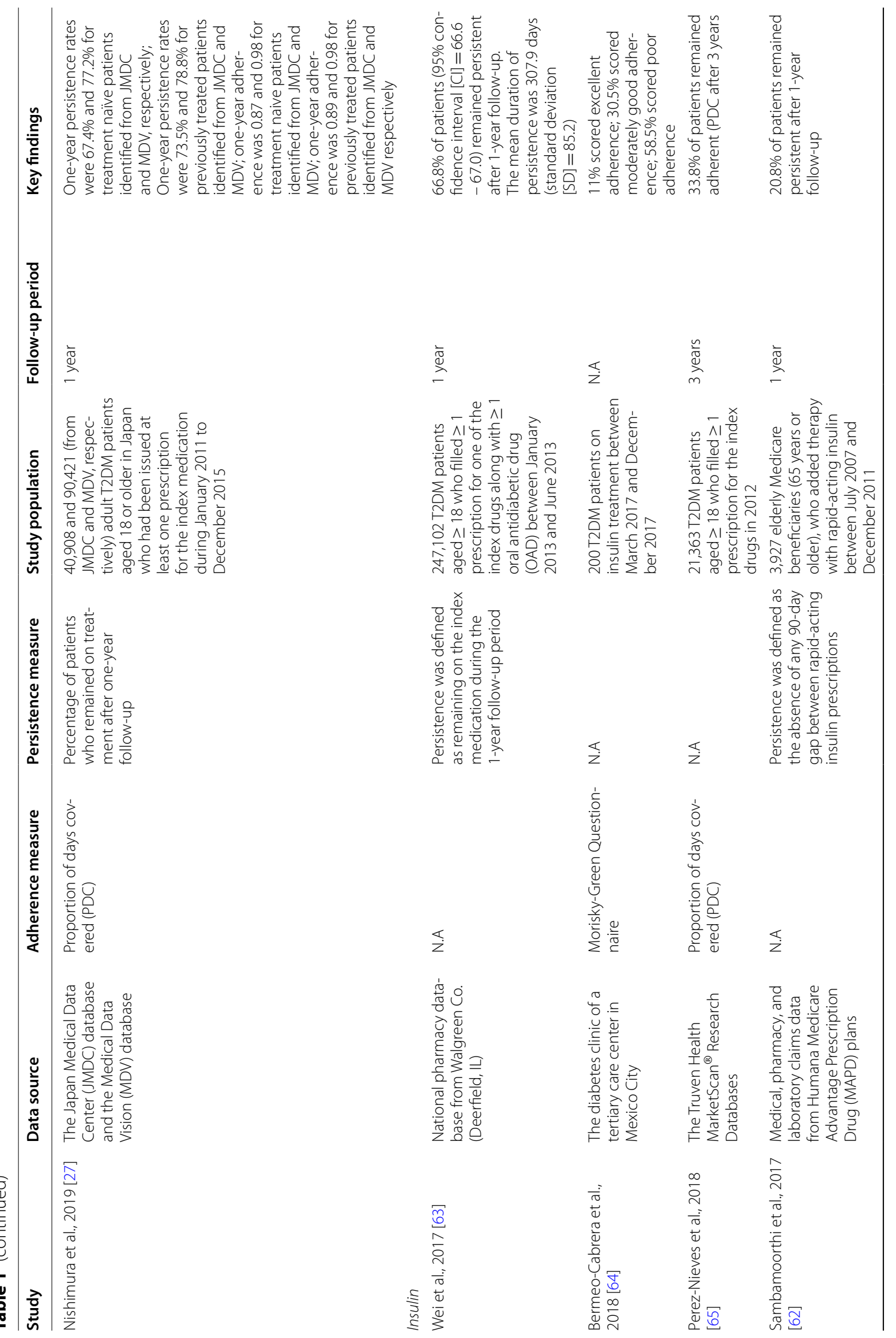




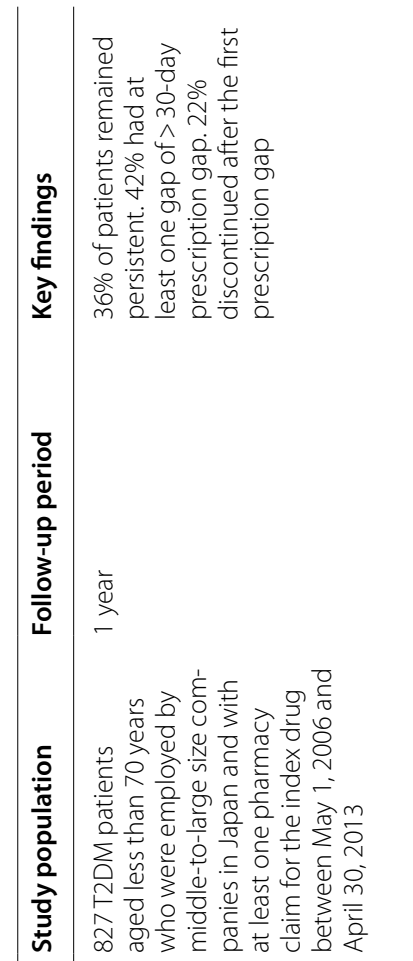

$\stackrel{n}{\Gamma}$
$\stackrel{+}{c}$
$\stackrel{0}{E}$
0
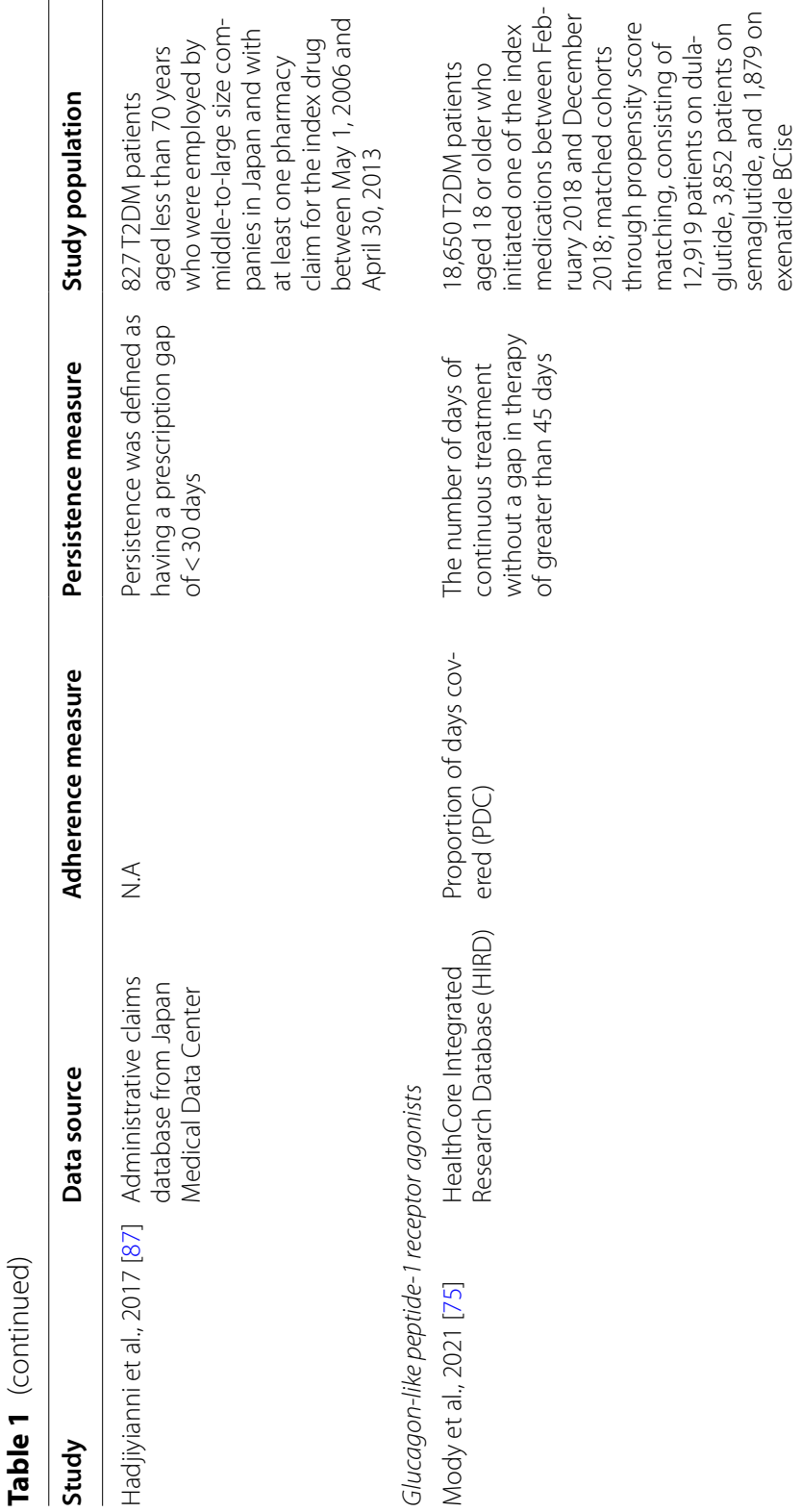
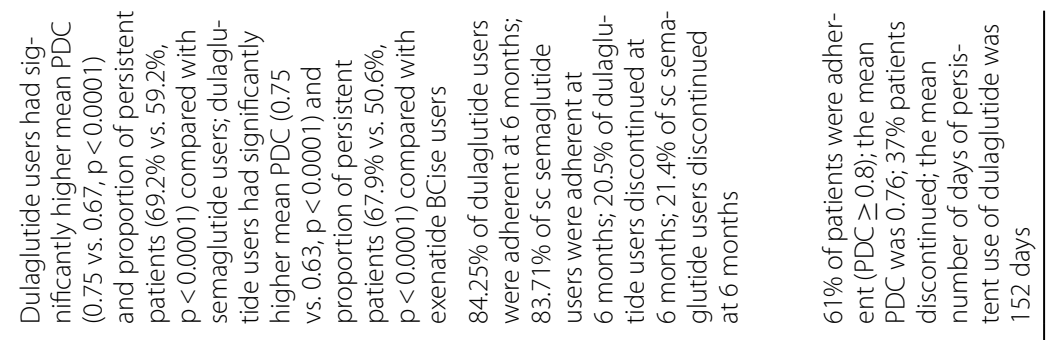

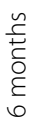

$\underset{\substack{\frac{\pi}{0} \\ m}}{n}$

$\infty$
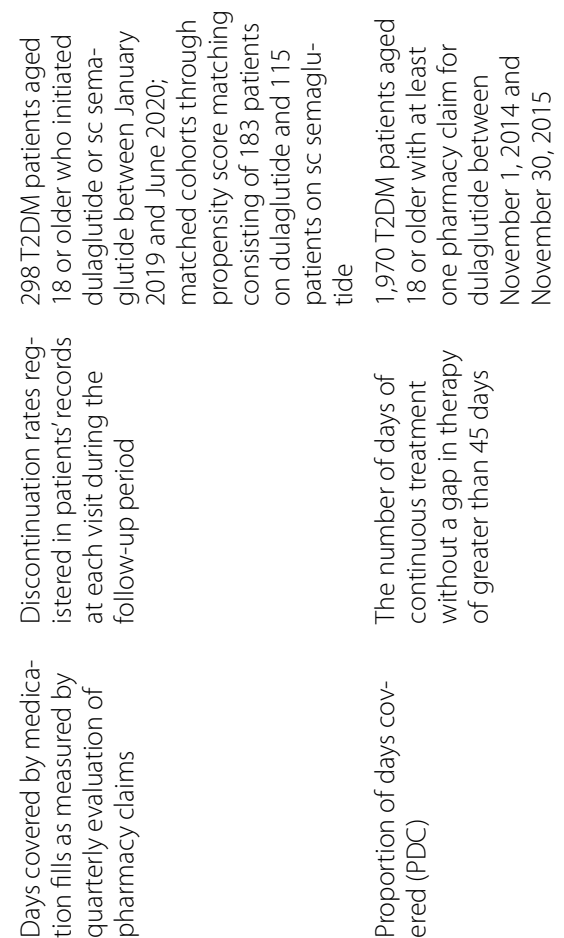

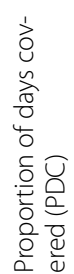
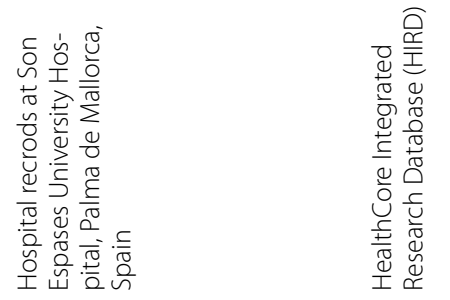

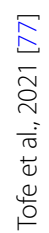




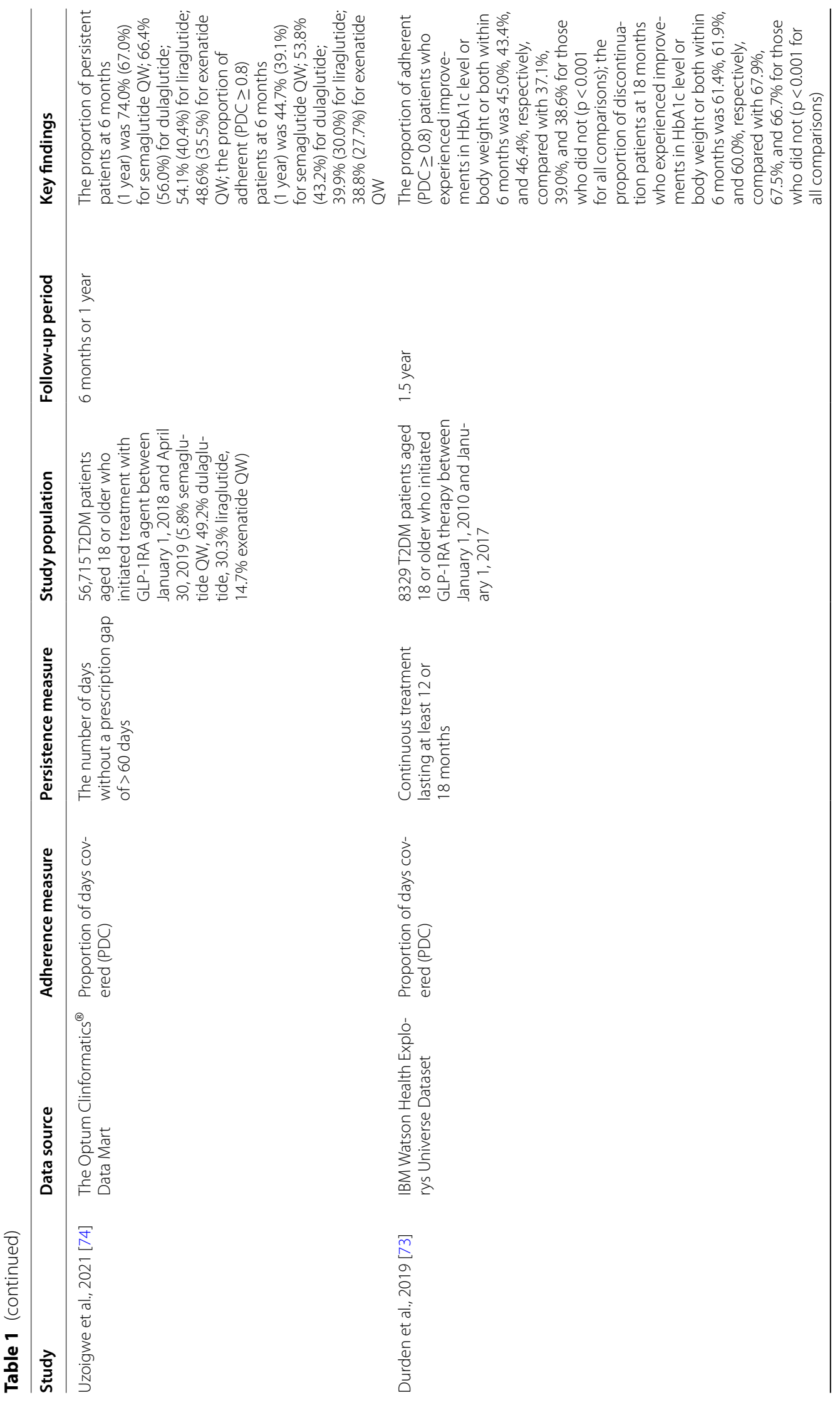




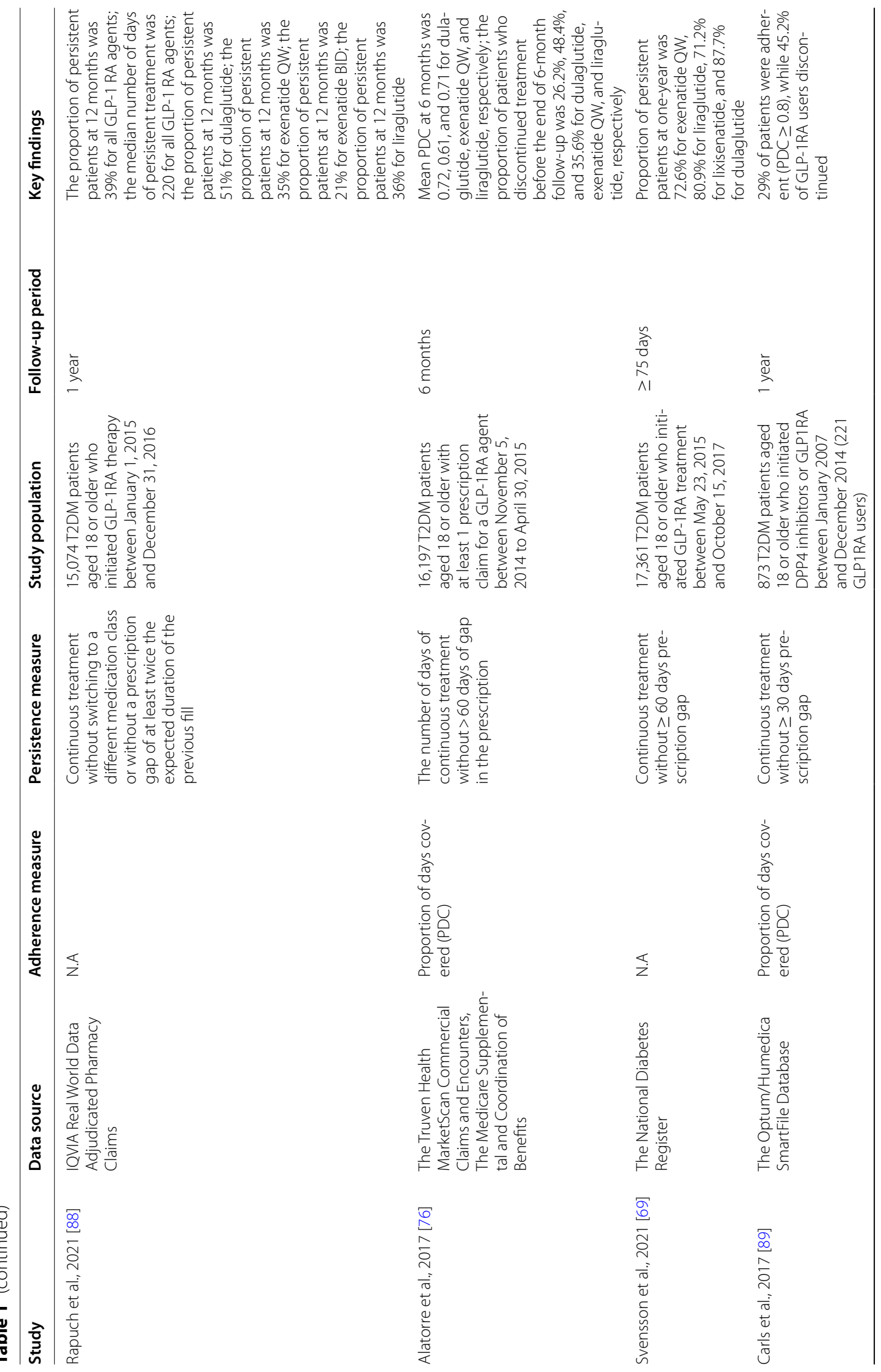




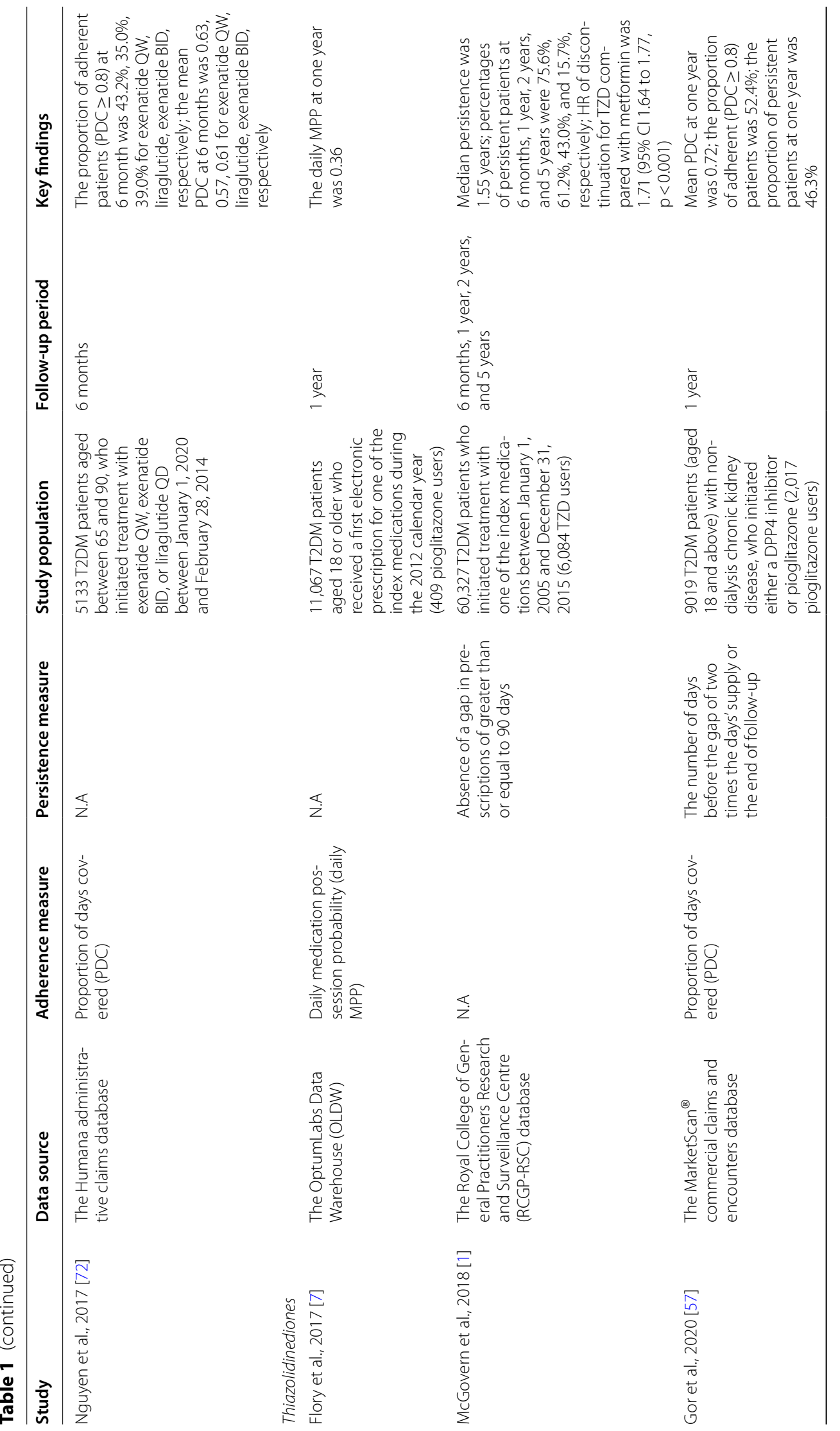




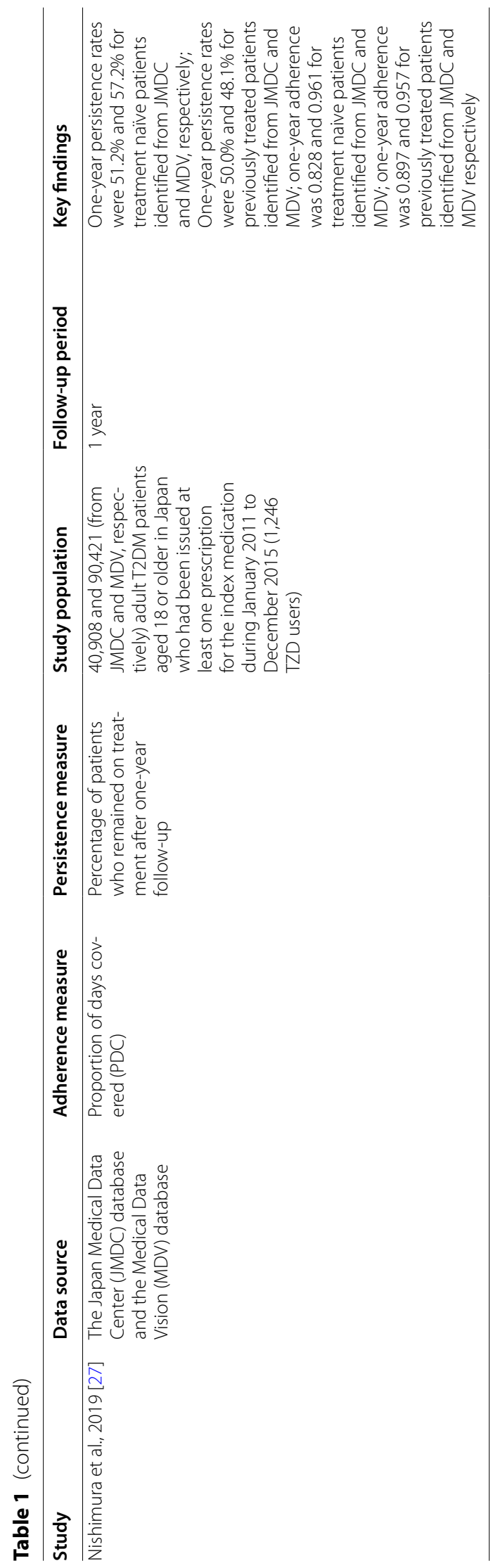


Table 2 Factors affecting adherence and persistence to metformin [19]

\begin{tabular}{|c|c|c|}
\hline Patient-related barriers & Practitioner-related barriers & Treatment-related barriers \\
\hline $\begin{array}{l}\text { Difficulties in understanding the rationale for } \\
\text { long-term metformin treatment }\end{array}$ & Poor health care team-patient relationship & $\begin{array}{l}\text { Regimen complexity, especially in patients with } \\
\text { multiple comorbid conditions }\end{array}$ \\
\hline $\begin{array}{l}\text { Difficulty swallowing; psychological difficulty } \\
\text { swallowing tablets }\end{array}$ & $\begin{array}{l}\text { Lack of times for in-depth communication with } \\
\text { patient }\end{array}$ & $\begin{array}{l}\text { Large size of or rough coating on metformin } \\
\text { tablets }\end{array}$ \\
\hline Memory problems (e.g., in older patients) & $\begin{array}{l}\text { Lack of awareness of problems with treatment } \\
\text { adherence }\end{array}$ & Inflexible treatment regimens \\
\hline $\begin{array}{l}\text { Socioeconomic factors (e.g., medication costs, } \\
\text { lack of support during treatment) }\end{array}$ & & Gastrointestinal side effects \\
\hline Cultural attitudes and beliefs & & \\
\hline
\end{tabular}

who used sitagliptin as an add-on to metformin (55.9\% versus 59.1\%, $\mathrm{p}<0.001$ ) [32].

Sulfonylureas are commonly associated with hypoglycemia and weight gain [33,34]. Approximately $20 \%$ of patients taking sulfonylureas may experience symptomatic hypoglycemia within six months after treatment initiation [35]. Moreover, sulfonylureas amplified weight gain in the first six months of treatment [36]. Such findings led to a speculation that the adverse events are the major reason for low adherence and persistence of sulfonylureas [33, 37]. However, no difference in treatment adherence was seen between patients who experienced hypoglycemic symptoms and those who did not [38]. Likewise, definitive evidence of the association between weight gain and poor adherence and persistence of sulfonylureas is still lacking.

\section{Sodium glucose co-transporter-2 inhibitors}

Sodium glucose cotransporter-2 (SGLT2) inhibitors, e.g., canagliflozin, dapagliflozin, and empagliflozin, are generally well tolerated $[39,40]$. The average PDC of SGLT2 inhibitors at one year was between 0.64 and 0.79 [41, 42]. Likewise, the proportion of patients who continued to take SGLT2 inhibitors at one year ranged between 44.3 and $72.1 \%[42,43]$.

There was a difference in adherence and persistence among individual SGLT2 inhibitors. Canagliflozin was associated with significantly higher adherence and persistence than dapagliflozin (OR [95\% CI] of adherence for canagliflozin compared with dapagliflozin: 1.29 [1.02-1.72]; HR [95\% CI] of discontinuation of dapagliflozin: 1.28 [1.15-1.42]; both $\mathrm{p}<0.001$ ) [41]. Treatment with canagliflozin is suspected to be associated with increased risks of lower extremity amputation and skeletal fractures, besides other adverse events commonly ascribed to SGLT2 inhibitors [44]. However, the impact of these adverse effects on the adherence and persistence of canagliflozin has not been fully investigated, warranting further studies. Similarly, empagliflozin users were significantly more adherent and persistent than dapagliflozin users (OR [95\% CI] of adherence and persistence of empagliflozin: 1.39 [1.29-1.51] and 1.14 [1.06-1.22], respectively; both $\mathrm{p}<0.01$ ) [42]. No study has directly compared the adherence and persistence rates between canagliflozin and empagliflozin.

The persistence rate of SGLT2 inhibitors was comparable to, and in some case even higher than, well-persisted antidiabetic medication classes (i.e., metformin and dipeptidyl peptidase-4 inhibitors). For example, SGLT2 inhibitor users were as persistent as metformin users (HR [95\% CI] of discontinuation of SGLT2 inhibitors: 1.04 [0.93-1.17], $\mathrm{p}=0.458$ ) [2]. Likewise, over 50\% of SGLT2 inhibitor users and metformin users remained persistent into the second year of treatment, while the majority of patients treated with other medication classes discontinued [2]. Furthermore, the discontinuation rate (i.e., having a prescription gap of $>90$ days) of canagliflozin users was $12 \%$ less $(\mathrm{p}<0.001)$ than that of sitagliptin (a dipeptidyl peptidase-4 inhibitor) users [45]

SGLT2 inhibitors block glucose reabsorption in the renal proximal tubules of the kidneys $[41,46,47]$. Their distinct mechanism of action entails a distinct set of adverse events, such as orthostatic hypotension, ketoacidosis, and most notably, genitourinary tract infections $[48,49]$. The unique safety profile of SGLT2 inhibitors led to a distinct factor for persistence. For example, higher estimated glomerular filtration rate (eGFR) was associated with significantly lower persistence rate (the beta coefficient [standard error] for discontinuation per oneunit increase in eGFR: $0.01[ \pm 0.00], \mathrm{p}<0.001)$ [49]. The increased likelihood of genitourinary tract infections due to the hyperfiltration of urinary glucose excretion was proposed as a reason for the association [49]. Similar conclusions were made by other studies $[48,50]$.

On the other hand, the factors for persistence commonly observed in other antidiabetic medications also applied to SGLT2 inhibitors. For example, younger age [41], female gender [41, 49], higher baseline anxiety [41], 
higher baseline HbA1c [49], and baseline insulin use [41, 51] were associated with significantly higher discontinuation rates in SGLT2 inhibitor users. In contrast, lower starting dose [41], perceived feeling of improved clinical outcome [41,51], and taking fewer number of concomitant medications $[49,51]$ were associated with significantly lower discontinuation rates in SGLT2 inhibitor users.

\section{Dipeptidyl peptidase-4 inhibitors}

As of July 2021, four dipeptidyl peptidase-4 (DPP4) inhibitors (sitagliptin, saxagliptin, linagliptin, and alogliptin) are in clinical use in the US [52]. Other DPP4 inhibitors that are being prescribed worldwide include anagliptin, tenegliptin, vildagliptin, omarigliptin, and trelagliptin [53]. DPP4 inhibitors prevent the degradation of glucagon like peptide-1 (GLP1) and stimulate postprandial insulin secretion in a glucose-dependent manner [54]. DPP4 inhibitors are generally well tolerated and pose little risk of hypoglycemia and weight gain [55, 56]. This safety profile leads to good adherence and persistence in DPP4 inhibitor users. The mean PDC at one year of DPP4 inhibitors ranged from 0.67 to $0.77[56,57]$. The percentage of patients who remained persistent to DPP4 inhibitors at one year was between 56.7 and $78.8 \%$ $[27,57]$. The median persistence of DPP4 inhibitors was approximately seventeen months $[2,58]$.

A comparison between individual DPP4 inhibitors showed that sitagliptin and saxagliptin demonstrated similar adherence and persistence rates [56]. On the other hand, sitagliptin and saxagliptin were associated with significantly better adherence and persistence than linagliptin (OR [95\% CI] of adherence for sitagliptin and saxagliptin: 1.40 [1.25-1.57] and 1.46 [1.29-1.66], respectively; HR [95\% CI] of discontinuation for sitagliptin and saxagliptin: 0.88 [0.82-0.94] and 0.85 [0.79-0.91], respectively; all $\mathrm{p}<0.001)$ [56].

The persistence of once-daily (QD) DPP4 inhibitors was comparable to that of twice-daily (BID) DPP4 inhibitors (HR [95\% CI] of discontinuation for BID regimen: 1.022 [0.994-1.050], $\mathrm{p}=0.1187$ ) [59]. Similarly, the difference between the adherence rates of BID regimen and QD regimen was not significant (OR [95\% CI] of adherence for BID regimen: 0.945 [0.780-1.145], $\mathrm{p}=0.5636$ ) [59]. On the other hand, QD regimen showed significantly higher adherence and persistence rates than once-weekly $(\mathrm{QW})$ regimen $(\mathrm{HR}[95 \% \mathrm{CI}]$ of discontinuation for QW regimens: 1.699 [1.585-1.822], $\mathrm{p}<0.0001$; OR [95\% CI] of adherence for QW regimen: 0.029 [0.024-0.036], $\mathrm{p}<0.0001$ ) [59]. However, there are also conflicting results. In a prospective study, adherence was improved by 0.1 point $(\mathrm{p}=0.03)$ on the Diabetes
Treatment Satisfactions Questionnaire (DTSQ) scale after patients switched from QD DPP4 inhibitors (i.e., sitagliptin, vildagliptin, alogliptin, linagliptin, and teneligliptin) to QW trelagliptin [60].

The persistence of DPP4 inhibitors is lower than that of metformin (HR [95\% CI] of discontinuation for DPP4 inhibitors: 1.43 [1.38-1.49], $\mathrm{p}<0.001$ ) [2]. However, DPP4 inhibitors are well adhered and persisted in T2DM patients with impaired kidney functions at all renal impairment stages [58]. Similarly, the adherence of DPP4 inhibitors in patients with chronic kidney disease (CKD) was significantly higher (OR [95\% CI] of adherence for DPP4 inhibitors: 1.41 [1.25-1.59], $\mathrm{p}<0.01)$ than pioglitazone, a well-established secondline therapy for T2DM patients with CKD [57].

The speculation that regimen complexity or the severity of diabetes may not necessarily lower adherence to DPP4 inhibitors [23] was supported by several studies [57-59]. Common reasons for discontinuing DPP4 inhibitors were inadequate glycemic control and intolerance, as with other antidiabetic medications [61].

\section{Insulin}

Insulin is key to improving the glycemic outcome in many T2DM patients. However, the adherence and persistence rates of insulin treatment are generally suboptimal. For example, one-year persistence rates of insulin treatment, measured as the percentage of patients who remained on therapy, were only $20-66.8 \%[62,63]$. Similarly, adherence to insulin was low; $58.5 \%$ of T2DM patients on insulin therapy scored poor adherence (scoring below 6) on the Morisky-Green Questionnaire [64]. The adherence to insulin treatment was inversely related to treatment period. The proportion of adherent patients (i.e., those with $P D C \geq 0.8$ ) on basal insulins dropped to $33.8 \%$ three years after treatment initiation [65]. Generally, basal insulins demonstrated better persistence than rapid-acting and short-acting insulins [2]. The major findings of previous studies that analyzed the adherence and persistence to insulin therapy are summarized in Table 1.

Simple reminding has been insufficient to improve the adherence and persistence of insulin treatment. In a recent randomized clinical trial, individualized interventions such as quarterly educational mailings, telephone consultation by pharmacists, and text reminders did not improve insulin persistence despite increasing intensity of the interventions [66]. Multifaceted approaches are crucial to adequately address insulin non-adherence and non-persistence. Table 3 summarizes the factors affecting adherence and persistence to insulin therapy. 
Table 3 Factors affecting adherence and persistence to insulin therapy

\begin{tabular}{ll}
\hline Factors that improve adherence and persistence & Factors that lower adherence and persistence \\
\hline $\begin{array}{l}\text { Using analog insulin rather than human or animal-derived insulin [90] } \\
\text { Using basal insulin rather than rapid- or short-acting insulin [2] }\end{array}$ & Having high baseline hypoglycemia or fear of hypoglycemia [64, 90-92] \\
$\begin{array}{l}\text { Being in age group (40-69) [90] } \\
\text { Experiencing improved glycemic control [93] }\end{array}$ & $\begin{array}{l}\text { Experiencing or having fear of weight gain [92, 93] } \\
\text { Having access to support system formed primarily of physicians and health- }\end{array}$ \\
$\begin{array}{l}\text { care professionals [93] } \\
\text { Using injection pen rather than vial or syringe [63] }\end{array}$ & Having complex regimen [64] \\
Having been treated for diabetes for longer duration [64] & Starting with higher dose [64] \\
Having higher baseline HbA1c level [90,92] & Feeling that insulin treatment interferes with daily activities [64] \\
\hline
\end{tabular}

Table 4 List of injectable GLP-1RA agents currently in clinical use worldwide

\begin{tabular}{ll}
\hline Drug & Dosing frequency \\
\hline Exenatide & Twice a day (BID) \\
Liraglutide & Once a day (QD) \\
Exenatide & Once a week (QW) \\
Albiglutide & Once a week (QW) \\
Dulaglutide prefilled pen & Once a week (QW) \\
Exenatide pen & Once a week (QW) \\
Lixisenatide & Once a day (QD) \\
Exenatide auto-injector & Once a week (QW) \\
Semaglutide & Once a week (QW) \\
\hline
\end{tabular}

\section{Glucagon-Like peptide-1 receptor agonists}

Glucagon-like peptide-1 receptor agonists (GLP-1RA) improve glycemic control and cardiovascular factors, reduce body weight, and rarely induce hypoglycemia [67]. GLP-1RA agents are preferred second-line treatment options for T2DM patients with cardiovascular comorbidities [68]. Furthermore, GLP-1RA agents are recommended as the first injectable medication before insulin [69]. As of 2021, nine formulations of injectable GLP-1RA agents have been approved worldwide (Table 4). Oral semaglutide (brand name: Rybelsus ${ }^{\circledR}$ ) was the first oral formulation of GLP-1RA approved by the US Food and Drug Administration for the treatment of T2DM [70].

The average PDC of injectable GLP-1RA agents at six months ranged from 0.61 to $0.76[71,72]$. The proportion of patients who continued treatment with injectable GLP-1RA at six months was between 32.1 and 74.0\% [73, 74]. The adherence and persistence of oral semaglutide remain to be seen.

Injectable GLP-1RA agents differ in dosing regimens, need for dose titration and reconstitution, and administration device features [75]. These differences led to differences in adherence and persistence rates among individual GLP-1RA agents. Dulaglutide showed significantly higher persistence than other GLP-1RA agents (HR [95\% CI] of discontinuation compared with dulaglutide: 2.5 [2.1-3.0] for exenatide QW, 1.6 [1.5-1.8] for liraglutide, 1.4 [1.3-1.5] for semaglutide, and 2.8 [2.3-3.3] for lixisenatide; all $\mathrm{p}<0.001)[69,75]$. Similarly, dulaglutide was associated with significantly higher adherence than other GLP-1RA agents (OR [95\% CI] of adherence compared with dulaglutide: 0.63 [0.55-0.73] for albiglutide, 0.32 [0.28-0.37] for exenatide BID, 0.48 [0.43-0.53] for exenatide QW, and 0.65 [0.59-0.71] for liraglutide; all $\mathrm{p}<0.05$ ) [76].

In general, GLP-1RA agents with QW regimen demonstrated significantly better adherence and persistence than GLP-1RA agents with QD or BID regimen $[67,72,74,76]$. In terms of delivery method, GLP-1RA agents using simple delivery systems (single-use pen or auto-injector device) had significantly higher adherence and persistence than GLP-1RA using multi-use pen or syringe [67, 71, 75-77]. Furthermore, experiencing early response (defined as improvements in HbA1c and body weight within six months after treatment initiation) was associated with significantly higher adherence and persistence in GLP-1RA users [73]. Other factors for the adherence and persistence of GLP-1RA agents are summarized in Table 5.

\section{Thiazolidinediones}

Thiazolidinediones (TZDs), including pioglitazone, are agonists of peroxisome proliferator-activated receptor- $\gamma$ (PPAR- $\gamma$ ) used in the treatment of T2DM. TZDs reduce plasma glucose by directly activating PPAR- $\gamma$ and improving insulin sensitivity [78, 79]. Furthermore, TZDs, along with DPP4 inhibitors, are the major treatment option for T2DM patients with impaired renal functions [57]. Despite their therapeutic benefits, few studies published since 2017 analyzed the adherence and persistence of TZDs due partly to the diminished market share (in case of rosiglitazone) or withdrawal from 
Table 5 Factors affecting the adherence and persistence to GLP-1RA

\begin{tabular}{ll}
\hline Reasons for treatment discontinuation & Factors for higher adherence and persistence \\
\hline Inadequate blood glucose control [67] & Initiating treatment with low dose [67, 75] \\
Gastrointestinal side effects (including nausea/vomiting) [67, 75,77] & Ease of use of injection device [75, 77] \\
Preference for oral medication over injection [95] & Weekly dosing rather than daily or twice daily dosing [72] \\
High cost [95] & Early (within 6 months) weight loss [73] \\
Injection site reaction [95] & Early (within 6 months) HbA1c level reduction [73] \\
Inadequate body weight reduction [73] & \\
Inconvenience of injection schedule [67,71] & \\
Injection-related concerns (including pain and fear) [76] & \\
\hline
\end{tabular}

the market (in case of troglitazone) [20, 80-82]. Still, the adherence of TZDs that are still being prescribed (e.g., pioglitazone) has been reported to range from 0.36 (measured in the daily MPP) to 0.72 (measured in PDC) $[7,57]$. The proportion of patients who remained persistent with TZDs for one-year varied from 46.3 to $75.6 \%$ (Table 1) [1, 57].

The safety issues surrounding TZDs significantly lowered adherence and persistence. For example, after the FDA issued a safety warning in June 2011 for pioglitazone and its possible link to bladder cancer, the discontinuation rate of pioglitazone increased significantly from $36.3 \%$ in the year 2010 to $41.0 \%$ in the year 2011 ( $p<0.01$ ) [57].

\section{Conclusion}

This article provided a comprehensive review of the adherence and persistence of major antidiabetic medications, i.e., metformin, sulfonylureas, SGLT2 inhibitors, DPP4 inhibitors, insulins, GLP-1RA agents, and TZDs. The adherence and persistence of major antidiabetic medications were not optimal, given that $\mathrm{PDC} \geq 0.8$ and the proportion of persistent patients $\geq 80 \%$ are generally recognized as optimum [25].

Most studies reported adherence in PDC and defined patients with $P D C \geq 0.8$ as adherent. Persistence was predominantly defined as continuous treatment without a prescription gap of more than 90 days. In most studies, the proportion of patients who remained persistent was used as the measure of the drug's persistence rate.

The highest rate of adherence and persistence was consistently observed in metformin users. Second to metformin were SGLT2 inhibitors. Injectable therapies such as insulin and GLP-1RA agents trailed low on the adherence and persistence rates. To the best of our knowledge, no studies published since the year 2017 analyzed the adherence and persistence of TZDs independently.

Most studies pointed out that the prevalence and severity of adverse events is associated with low medication adherence and persistence. Baseline characteristics (e.g., baseline HbA1c level), socioeconomic factors (e.g., medication costs and insurance status), demographic information (e.g., age, gender, or ethnicity), and comorbidity profiles also had significant impacts on adherence and persistence in T2DM patients.

It is important to note that reports on the adherence and persistence rates varied, depending on study design, data source, and patient sample. Using different definitions of adherence (e.g., daily MPP or PDC) and of persistence (e.g., continuous treatment without a prescription gap of over 60 days or 90 days) may have also contributed to the variations in the findings. In the similar vein, primary adherence (i.e., the rate at which patients fill prescriptions for the first time after treatment initiation) is critical for timely treatment of both acute and chronic conditions [83]. Despite its clinical significance, we found that the primary adherence of antidiabetic medications has not been extensively covered in the literature. Moreover, most studies measured adherence and persistence over one year after the initiation of antidiabetic drugs. Because these measures are inversely related to the duration of follow-up, using different observation periods may have led to different results. Lastly, most studies relied on electronic health records (EHR) and claims data to analyze the adherence and persistence. Thus, it should be acknowledged that a purely claims-based study may have underestimated adherence and persistence by leaving out the patients who paid out of pocket. On the contrary, a purely EHR-based study may have overestimated the adherence and persistence because there are significantly more provider attempts to prescribe a drug than there are patients voluntarily taking the drug in the long term [7].

This review article aimed to address the following points. First, this review article offers a concise summary of the adherence and persistence rates of antidiabetic medications that comprise of the most of the proportional market share worldwide. Secondly, the 
findings summarized in this article may help guide the clinicians and the patients to make informed treatment decisions. Study results from randomized clinical trials confirm the effectiveness and safety of a medication. However, the results may not always translate into everyday clinical benefit, as there are diverse factors at work, including adherence and persistence. In this light, knowing the treatment-related factors and patient-level information affecting the behavior of medication (e.g., treatment adherence and persistence) use may equip the medical community to identify the beneficiaries of the drug's effectiveness with higher granularity. Lastly, information contained in this article may provide insight into the paths for the development of new antidiabetic medications or injection devices that are more amenable to fostering adherence and persistence.

Because the treatment of diabetes relies heavily on antidiabetic medications, along with lifestyle modification, dietary interventions, and other medications for comorbid conditions, ensuring adherence and persistence is key to adequately managing the disease. Moreover, adherence and persistence are clinically important phenomena with implications for research and clinical practice. Therefore, clinicians should be aware of the challenges concerning adherence and persistence to antidiabetic medications. It is imperative that they pay attention to how the multifactorial nature of medication non-use undermines patients' quality of life and clinical outcomes.

\section{Abbreviations \\ HbA1c: Glycated hemoglobin; T2DM: Type 2 diabetes mellitus; MPP: Medica- tion possession probability; OR: Odds ratio; $95 \% \mathrm{Cl}$ : $95 \%$ Confidence interval; PDC: Proportion of days covered; HR: Hazard ratio; SGLT2: Sodium glucose cotrasporter-2; eGFR: Estimated glomerular filtration rate; DPP4: Dipeptidyl peptidase-4; GLP1: Glucagon like peptide-1; QD: Once-daily; BID: Twice-daily; QW: Once-weekly; DTSQ: Diabetes Treatment Satisfaction Questionnaire; CKD: Chronic kidney disease; TZD: Thiazolidinediones; PPAR-y: Peroxisome proliferator-activated receptor- $\gamma$; EHR: Electronic health records.}

\section{Acknowledgements}

Not applicable.

\section{Authors' contributions}

DL has carried out the literature review and drafted the manuscript. HL has helped drafting the manuscript and substantively revised it. Both authors read and approved the final manuscript.

\section{Funding}

This research was supported by the BK21FOUR Program of the National Research Foundation of Korea (NRF) funded by the Ministry of Education (5120200513755).

\section{Availability of data and materials}

Data sharing is not applicable to this article as no datasets were generated or analyzed during the current study.

\section{Declarations}

Ethics approval and consent to participate

Not applicable.

\section{Consent for publication}

Not applicable.

\section{Competing interests}

The authors declare that there is no conflict of interest.

\section{Author details}

${ }^{1}$ Department of Molecular Medicine and Biopharmaceutical Sciences, Graduate School of Convergence Science and Technology, Seoul National University, Seoul 08826, South Korea. ${ }^{2}$ Department of Applied Biomedical Engineering, Graduate School of Convergence Science and Technology, Seoul National University, Seoul 08826, South Korea. ${ }^{3}$ Department of Clinical Pharmacology and Therapeutics, Seoul National University College of Medicine and Hospital, 103 Daehak-ro, Jongno-gu, Seoul 110-799, Republic of Korea. ${ }^{4}$ Center for Convergence Approaches in Drug Development, Graduate School of Convergence Science and Technology, Seoul National University, Seoul 08826, South Korea. ${ }^{5}$ Advanced Institute of Convergence Technology, Suwon 16229, South Korea.

Received: 19 November 2021 Accepted: 5 January 2022

Published online: 15 January 2022

\section{References}

1. McGovern A, et al. A class comparison of medication persistence in people with type 2 diabetes: a retrospective observational study. Diabetes Therapy. 2018;9(1):229-42.

2. McGovern A, et al. Comparison of medication adherence and persistence in type 2 diabetes: a systematic review and meta-analysis. Diabetes Obes Metab. 2018;20(4):1040-3.

3. Jermendy $\mathrm{G}$, et al. Persistence of initial oral antidiabetic treatment in patients with type 2 diabetes mellitus. Med Sci Monit Int Med J Exp Clin Res. 2012;18(2):72.

4. Organization WH. Adherence to long-term therapies: evidence for action. World Health Organization; 2003.

5. Abegunde DO, et al. The burden and costs of chronic diseases in lowincome and middle-income countries. Lancet. 2007;370(9603):1929-38.

6. Asche C, LaFleur J, Conner C. A review of diabetes treatment adherence and the association with clinical and economic outcomes. Clin Ther. 2011;33(1):74-109.

7. Flory J, et al. Comparative adherence to diabetes drugs: an analysis of electronic health records and claims data. Diabetes Obes Metab. 2017;19(8):1184-7.

8. Jha AK, et al. Greater adherence to diabetes drugs is linked to less hospital use and could save nearly $\$ 5$ billion annually. Health Aff. 2012;31(8):1836-46.

9. Kennedy-Martin T, Boye KS, Peng X. Cost of medication adherence and persistence in type 2 diabetes mellitus: a literature review. Patient Prefer Adherence. 2017;11:1103.

10. Iglay K, et al. Meta-analysis of studies examining medication adherence, persistence, and discontinuation of oral antihyperglycemic agents in type 2 diabetes. Curr Med Res Opin. 2015;31(7):1283-96.

11. Baser $\mathrm{O}$, et al. Real-world outcomes of initiating insulin glargine-based treatment versus premixed analog insulins among US patients with type 2 diabetes failing oral antidiabetic drugs. ClinicoEcon Outcomes Res CEOR. 2013;5:497.

12. Aikens JE, Piette JD. Longitudinal association between medication adherence and glycaemic control in type 2 diabetes. Diabet Med. 2013;30(3):338-44.

13. Rozenfeld $Y$, et al. Oral antidiabetic medication adherence and glycemic control in managed care. Am J Managed Care. 2008;14(2):71-5. 
14. Hong JS, Kang HC. Relationship between oral antihyperglycemic medication adherence and hospitalization, mortality, and healthcare costs in adult ambulatory care patients with type 2 diabetes in South Korea. Med Care. 2011;49:378-84.

15. Currie CJ, et al. The impact of treatment noncompliance on mortality in people with type 2 diabetes. Diabetes Care. 2012;35(6):1279-84

16. Egede $L E$, et al. Medication nonadherence in diabetes: Iongitudinal effects on costs and potential cost savings from improvement. Diabetes Care. 2012:35(12):2533-9.

17. Sabaté E, Sabaté E. Adherence to long-term therapies: evidence for action. World Health Organization; 2003.

18. Chandran A, et al. Adherence to insulin pen therapy is associated with reduction in healthcare costs among patients with type 2 diabetes mellitus. Am Health Drug Benefits. 2015;8(3):148.

19. Christofides EA. Practical insights into improving adherence to metformin therapy in patients with type 2 diabetes. Clin Diabetes. 2019;37(3):234-41.

20. Montvida O, et al. Long-term trends in antidiabetes drug usage in the US: real-world evidence in patients newly diagnosed with type 2 diabetes. Diabetes Care. 2018;41(1):69-78.

21. Association AD. Summary of revisions: standards of medical care in diabetes-2019. Diabetes Care. 2019;42(Supplement 1):S4-6.

22. Maruthur NM, et al. Diabetes medications as monotherapy or metforminbased combination therapy for type 2 diabetes: a systematic review and meta-analysis. Ann Intern Med. 2016;164(11):740-51.

23. Cramer JA. A systematic review of adherence with medications for diabetes. Diabetes Care. 2004;27(5):1218-24.

24. Nau DP. Proportion of days covered (PDC) as a preferred method of measuring medication adherence. Springfield, VA: Pharmacy Quality Alliance; 2012

25. Karve S, et al. Good and poor adherence: optimal cut-point for adherence measures using administrative claims data. Curr Med Res Opin. 2009;25(9):2303-10.

26. Horsburgh $\mathrm{S}$, et al. Patterns of metformin monotherapy discontinuation and reinitiation in people with type 2 diabetes mellitus in New Zealand. PLOS ONE. 2021;16(4): e0250289.

27. Nishimura R, et al. Treatment patterns, persistence and adherence rates in patients with type 2 diabetes mellitus in Japan: a claims-based cohort study. BMJ Open. 2019;9(3): e025806.

28. Flory $\mathrm{JH}$, et al. Identifying prevalence and risk factors for metformin non-persistence: a retrospective cohort study using an electronic health record. BMJ Open. 2018:8(7): e021505.

29. Shani M, Lustman A, Vinker S. Diabetes medication persistence, different medications have different persistence rates. Prim Care Diabetes. 2017;11(4):360-4

30. Flory JH, Mushlin Al. Effect of cost and formulation on persistence and adherence to initial metformin therapy for type 2 diabetes. Diabetes Care. 2020;43(6):e66-7.

31. Bell KF, et al. Comparing medication adherence and persistence among patients with type 2 diabetes using sodium-glucose cotransporter 2 inhibitors or sulfonylureas. Am Health Drug Benefits. 2017:10(4):165.

32. Bloomgarden ZT, et al. Adherence, persistence, and treatment discontinuation with sitagliptin compared with sulfonylureas as add-ons to metformin: a retrospective cohort database study: 在二甲双胍治疗 的基础上比较加用西格列汀治疗与加用磺嫝类药物治疗的依从 性, 持久性以及治疗中止: 一项回顾性队列数据库研究. J Diabetes. 2017;9(7):677-88

33. Nunes AP, et al. Hypoglycaemia seriousness and weight gain as determinants of cardiovascular disease outcomes among sulfonylurea users. Diabetes Obes Metab. 2017;19(10):1425-35.

34. Thulé PM, Umpierrez G. Sulfonylureas: a new look at old therapy. Curr Diabetes Rep. 2014;14(4):473.

35. Jennings AM, Wilson RM, Ward JD. Symptomatic hypoglycemia in NIDDM patients treated with oral hypoglycemic agents. Diabetes Care. 1989;12(3):203-8

36. Carls $\mathrm{G}$, et al. Real-world weight change among patients treated with glucagon-like peptide-1 receptor agonist, dipeptidyl peptidase-4 inhibitor and sulfonylureas for type 2 diabetes and the influence of medication adherence. Obes Sci Pract. 2017;3(3):342-51.
37. Pi-Sunyer FX. The impact of weight gain on motivation, compliance, and metabolic control in patients with type 2 diabetes mellitus. Postgrad Med. 2009:121(5):94-107.

38. Popoviciu S, Alionescu A, Sisic I. Prevalence of hypoglycemia, treatment satisfaction, adherence and their associations with glycemic goals in patients with type 2 diabetes mellitus treated with sulfonylureas: findings from the Real-Life Effectiveness and Care Patterns of Diabetes Management (RECAP-DM) in Romania. Romanian J Diabetes Nutr Metab Dis. 2019:26(1):55-64.

39. Khunti N, Khunti N, Khunti K. Adherence to type 2 diabetes management. Br J Diabetes. 2019;19(2):99-104

40. Hirsch IB, Molitch ME. Clinical decisions. Glycemic management in a patient with type 2 diabetes. N Engl J Med. 2013;369(14):1370-2.

41. Cai J, Divino V, Burudpakdee C. Adherence and persistence in patients with type 2 diabetes mellitus newly initiating canagliflozin, dapagliflozin, DPP-4s, or GLP-1s in the United States. Curr Med Res Opin. 2017;33(7):1317-28.

42. Ofori-Asenso R, et al. Adherence, persistence, and switching among people prescribed sodium glucose co-transporter 2 inhibitors: a nationwide retrospective cohort study. Adv Therapy. 2019;36(11):3265-78

43. Ito $Y$, et al. Real-world effectiveness of sodium glucose co-transporter-2 inhibitors in Japanese patients with diabetes mellitus. Diabetes Therapy. 2019;10(6):2219-31.

44. Neal B, et al. Canagliflozin and cardiovascular and renal events in type 2 diabetes. N Engl J Med. 2017;377(7):644-57.

45. Thayer S, et al. HbA1c outcomes in patients treated with canagliflozin versus sitagliptin in US health plans. Clin Ther. 2017;39(10):2061-72.

46. Chao EC, Henry RR. SGLT2 inhibition-a novel strategy for diabetes treatment. Nat Rev Drug Discov. 2010;9(7):551-9.

47. Jabbour S, Goldstein B. Sodium glucose co-transporter 2 inhibitors: blocking renal tubular reabsorption of glucose to improve glycaemic control in patients with diabetes. Int J Clin Pract. 2008;62(8):1279-84.

48. Tumminia A, et al. Efficacy, renal safety and tolerability of sodiumglucose cotransporter 2 inhibitors (SGLT2i) in elderly patients with type 2 diabetes: a real-world experience. Prim Care Diabetes. 2021;15(2):283-8.

49. Fadini $G$, et al. Predictors of early discontinuation of dapagliflozin versus other glucose-lowering medications: a retrospective multicenter realworld study. J Endocrinol Invest. 2020;43(3):329-36.

50. Lorenzo MG et al. 4CPS-013 Discontinuation of sodium-glucose cotransporter 2 inhibitors due to recurrent genitourinary infections. British Medical Journal Publishing Group. 2018.

51. Buysman EK, et al. Retrospective study on the impact of adherence in achieving glycemic goals in type 2 diabetes mellitus patients receiving canagliflozin. Adv Therapy. 2017;34(4):937-53.

52. Srinivasa Venkata Siva Kumar Kasina KMB. Dipeptidyl Peptidase IV (DPP IV) inhibitors. StatPerals Publishing, Treasure Island (FL); 2021.

53. Gallwitz B. Clinical use of DPP-4 inhibitors. Front Endocrinol. 2019;10:389.

54. Bhavadasan K, Davis AM, Kolanthavel B. Impact of dipeptidyl peptidase-4 inhibitors on glycemic control and cardiovascular safety with adherence: an overview. Dubai Diabetes Endocrinol J. 2019;25(3-4):90-9.

55. Dicker D. DPP-4 inhibitors: impact on glycemic control and cardiovascular risk factors. Diabetes Care. 2011;34(Supplement 2):S276-8.

56. Rascati $\mathrm{KL}$, et al. Adherence, persistence, and health care costs for patients receiving dipeptidyl peptidase-4 inhibitors. J Manag Care Spec Pharm. 2017;23(3):299-306.

57. Gor D, et al. Adherence and persistence with DPP-4 inhibitors versus pioglitazone in type 2 diabetes patients with chronic kidney disease: a retrospective claims database analysis. J Manag Care Spec Pharm. 2020;26(1):67-75

58. Kadowaki T, et al. Persistence of oral antidiabetic treatment for type 2 diabetes characterized by drug class, patient characteristics and severity of renal impairment: a Japanese database analysis. Diabetes Obes Metab. 2018;20(12):2830-9

59. Oh A, et al. Comparison of persistence and adherence between DPP-4 inhibitor administration frequencies in patients with type 2 diabetes mellitus in Japan: a claims-based cohort study. Curr Med Res Opin. 2020:36(3):387-95 
60. Ito $\mathrm{H}$, et al. Changes in medication adherence and unused drugs after switching from daily dipeptidyl peptidase-4 inhibitors to once-weekly trelagliptin in patients with type 2 diabetes. Diabetes Res Clin Pract. 2019;153:41-8.

61. Ogundipe $\mathrm{O}$, et al. Real-world adherence, persistence, and in-class switching during use of dipeptidyl peptidase-4 inhibitors: a systematic review and meta-analysis involving 594,138 patients with type 2 diabetes. Acta Diabetol. 2021;58(1):39-46.

62. Sambamoorthi $U$, et al. Persistence with rapid-acting insulin and its association with A1C level and severe hypoglycemia among elderly patients with type 2 diabetes. Curr Med Res Opin. 2017;33(7):1309-16.

63. Wei $W$, et al. Benchmarking insulin treatment persistence among patients with type 2 diabetes across different US payer segments. J Manag Care Spec Pharm. 2017;23(3):278-90

64. Bermeo-Cabrera J, et al. Insulin adherence in type 2 diabetes in Mexico: behaviors and barriers. J Diabetes Res. 2018. https://doi.org/10.1155/ 2018/3190849.

65. Perez-Nieves $M$, et al. Adherence to basal insulin therapy among people with type 2 diabetes: a retrospective cohort study of costs and patient outcomes. Diabetes Therapy. 2018:9(3):1099-111.

66. Lauffenburger J, et al. Effect of targeted insulin adherence interventions for glycemic control with predictive analytics: the TARGIT-diabetes randomized clinical trial. Circulation. 2018;138(Suppl_1):A11795.

67. Guerci B, et al. Efficacy and adherence of glucagon-like peptide-1 receptor agonist treatment in patients with type 2 diabetes mellitus in real-life settings. Diabetes Metab. 2019;45(6):528-35.

68. Association AD. 9. Pharmacologic approaches to glycemic treatment: standards of medical care in diabetes - 2020. Diabetes Care. 2020;43(Supplement 1):S98-110.

69. Svensson AM, et al. Treatment persistence in patients with type 2 diabetes treated with glucagon-like peptide-1 receptor agonists in clinical practice in Sweden. Diabetes Obes Metab. 2021;23(3):720-9.

70. Nordisk N. Rybelsus (semaglutide) tablets [prescribing information]. Plainsboro, NJ, Novo Nordisk, 2019.

71. Mody R, et al. Real-world effectiveness, adherence and persistence among patients with type 2 diabetes mellitus initiating dulaglutide treatment. Curr Med Res Opin. 2018;34(6):995-1003.

72. Nguyen H, Dufour R, Caldwell-Tarr A. Glucagon-like peptide-1 receptor agonist (GLP-1RA) therapy adherence for patients with type 2 diabetes in a medicare population. Adv Therapy. 2017;34(3):658-73.

73. Durden $E$, et al. The effect of early response to GLP-1 RA therapy on longterm adherence and persistence among type 2 diabetes patients in the United States. J Manag Care Spec Pharm. 2019;25(6):669-80.

74. Uzoigwe C, et al. Semaglutide once-weekly persistence and adherence versus other GLP-1 RAs in patients with type 2 diabetes in a US real-world setting. Diabetes Therapy. 2021;12(5):1475-89.

75. Mody R, et al. Adherence and persistence among patients with type 2 diabetes initiating dulaglutide compared with semaglutide and exenatide BCise: 6-month follow-up from US real-world data. Diabetes Obes Metab. 2021;23(1):106-15.

76. Alatorre C, et al. Treatment patterns in patients with type 2 diabetes mellitus treated with glucagon-like peptide-1 receptor agonists: higher adherence and persistence with dulaglutide compared with once-weekly exenatide and liraglutide. Diabetes Obes Metab. 2017;19(7):953-61.

77. Tofé $\mathrm{S}$, et al. An observational study evaluating effectiveness and therapeutic adherence in patients with Type 2 diabetes initiating dulaglutide vs subcutaneous semaglutide in Spain. Endocr Metab Sci. 2021;2: 100082

78. Kemnitz JW, et al. Pioglitazone increases insulin sensitivity, reduces blood glucose, insulin, and lipid levels, and lowers blood pressure, in obese, insulin-resistant rhesus monkeys. Diabetes. 1994;43(2):204-11.

79. Lebovitz $\mathrm{HE}$, et al. Rosiglitazone monotherapy is effective in patients with type 2 diabetes. J Clin Endocrinol Metab. 2001;86(1):280-8.

80. Cheng D, Gao H, Li W. Long-term risk of rosiglitazone on cardiovascular events - a systematic review and meta-analysis. Endokrynol Pol. 2018;69(4):381-94.

81. Davidson MA, et al. Thiazolidinedione drugs in the treatment of type 2 diabetes mellitus: past, present and future. Crit Rev Toxicol. 2018;48(1):52-108.

82. Tang $\mathrm{H}$, et al. Pioglitazone and bladder cancer risk: a systematic review and meta-analysis. Cancer Med. 2018;7(4):1070-80.
83. Fischer MA, et al. Primary medication non-adherence: analysis of 195,930 electronic prescriptions. J Gen Intern Med. 2010;25(4):284-90.

84. Naffaa $M$, et al. Adherence to metformin and the onset of rheumatoid arthritis: a population-based cohort study. Scand J Rheumatol. 2020:49(3):173-80

85. Walker EA, et al. Long-term metformin adherence in the diabetes prevention program outcomes study. BMJ Open Diabetes Res Care. 2020;8(1): e001537.

86. Moura CS, et al. Treatment discontinuation and clinical events in type 2 diabetes patients treated with dipeptidyl peptidase-4 inhibitors or NPH insulin as third-line therapy. J Diabetes Res. 2018. https://doi.org/10.1155/ 2018/4817178.

87. Hadjiyianni I, et al. Basal insulin persistence, associated factors, and outcomes after treatment initiation: a retrospective database study among people with type 2 diabetes mellitus in Japan. Diabetes Therapy. 2017:8(1):149-66.

88. Rapuch SZ, et al. Treatment patterns and persistence with GLP-1 RA treatments among patients with type 2 diabetes in France: a retrospective cohort analysis. Diabetes Therapy. 2021;12(5):1553-67.

89. Carls GS, et al. Understanding the gap between efficacy in randomized controlled trials and effectiveness in real-world use of GLP-1 RA and DPP-4 therapies in patients with type 2 diabetes. Diabetes Care. 2017:40(11):1469-78.

90. He $X$, et al. Insulin adherence and persistence among Chinese patients with type 2 diabetes: a retrospective database analysis. Patient Prefer Adherence. 2017;11:237.

91. Li P, et al. Early hypoglycaemia and adherence after basal insulin initiation in a nationally representative sample of medicare beneficiaries with type 2 diabetes. Diabetes Obes Metab. 2019;21(11):2486-95.

92. Perez-Nieves $M$, et al. Basal insulin initiation use and experience among people with type 2 diabetes mellitus with different patterns of persistence: results from a multi-national survey. Curr Med Res Opin. 2017;33(10):1833-42.

93. Idris I, et al. Associated factors that influenced persistence with basal analog insulin therapy among people with type 2 diabetes: an exploratory analysis from a UK real-world sample. Prim Care Diabetes. 2019;13(2):106-12.

94. Davies M, et al. Real-world factors affecting adherence to insulin therapy in patients with Type 1 or Type 2 diabetes mellitus: a systematic review. Diabet Med. 2013;30(5):512-24.

95. Sikirica MV, et al. Reasons for discontinuation of GLP1 receptor agonists: data from a real-world cross-sectional survey of physicians and their patients with type 2 diabetes. Diabetes Metab Syndrome Obes Targets Therapy. 2017;10:403.

\section{Publisher's Note}

Springer Nature remains neutral with regard to jurisdictional claims in published maps and institutional affiliations.

Ready to submit your research? Choose BMC and benefit from

- fast, convenient online submission

- thorough peer review by experienced researchers in your field

- rapid publication on acceptance

- support for research data, including large and complex data types

- gold Open Access which fosters wider collaboration and increased citations

- maximum visibility for your research: over $100 \mathrm{M}$ website views per year

At BMC, research is always in progress.

Learn more biomedcentral.com/submissions 